\title{
ANÁLISE DA PERCEPÇÃO DOS DISCENTES DO CURSO DE GRADUAÇÃO EM CIÊN- CIAS CONTÁBEIS SOBRE EXPRESSÕES DE INCERTEZA CONTIDAS NOS PRONUNCIA- MENTOS EMITIDOS PELO COMITÊ DE PRONUNCIAMENTOS CONTÁBEIS
}

\author{
ANALYSIS OF THE PERCEPTION OF ACCOUNTING STUDENTS ABOUT THE EXPRES- \\ SION OF UNCERTAINTY PRESENTS IN THE STATEMENTS ISSUED BY THE BRAZILIAN \\ ACCOUNTING PRONOUNCEMENTS COMMITTEE
}

\author{
Fernanda Franco de Sá ${ }^{a}$; Rodrigo Fernandes Malaquias ${ }^{b}$ \\ ${ }^{a}$ Bacharel em Ciências Contábeis pela Universidade Federal de Uberlândia - UFU \\ Uberlândia, $M G$-Brasil; E-mail: fernandafranco_ds@hotmail.com \\ ${ }^{b}$ Professor da Faculdade de Ciências Contábeis da Universidade Federal de Uberlândia. \\ Doutorado em Administração de Empresas pela Fundação Getúlio Vargas - FGV \\ Uberlândia, $M G$-Brasil; E-mail: rodrigofmalaquias@yahoo.com.br
}

\section{Resumo}

Este trabalho apresentou como objetivo geral analisar a percepção dos discentes do curso de graduação em Ciências Contábeis sobre a interpretação das expressões de incerteza contidas nos Pronunciamentos Técnicos do CPC (Comitê de Pronunciamentos Contábeis) sobre Instrumentos Financeiros. A escolha de tais pronunciamentos se deu em razão de as operações com instrumentos financeiros serem complexas e terem se tornado um tema polêmico, devido ao grande impacto que se estima causar nos resultados das entidades. Uma amostra composta por 104 questionários foi analisada de acordo com variáveis de critério e por meio dos testes estatísticos e os principais resultados evidenciaram diferenças estatisticamente significativas na interpretação das expressões analisadas, o que se alinha com resultados de estudos anteriores. Concluiu-se que interpretações distintas de uma mesma expressão podem acarretar contabilizações diferenciadas de um mesmo evento, influenciando, assim, nas tomadas de decisões dos usuários das normas e, portanto, na comparabilidade das demonstrações contábeis.

Palavras-chave: CPC; Expressões de Incerteza; Instrumentos Financeiros.

\section{Abstract}

This study proposes to analyze the perceptions of accounting students about the interpretation of uncertainty expressions presents in the Financial Instruments Statements. The choice of such Statements happened as a result of transactions with financial instruments are complex and have become a controversial issue because of the large impact that is estimated to cause the results of the entities. A sample of 104 questionnaires was analyzed according to the criterion variables and by means of statistical tests, and the main results showed statistically significant differences in interpretation of the terms analyzed, which is in line with results of previous studies. It was concluded that different interpretations of the same expression can lead to different decision of how to account the same event, thus influencing, the decision making of users of the standards and therefore comparability of financial statements.

Keywords: CPC; Expressions of Uncertainty; Financial Instruments. 


\section{INTRODUÇÃO}

O principal objetivo da Contabilidade, conforme Iudícibus (2000, p. 28), “é fornecer informação econômica relevante para que cada usuário possa tomar suas decisões e realizar seus julgamentos com segurança".

Segundo Feitosa (2001), ao longo do tempo, a contabilidade vem evoluindo em resposta às necessidades locais, sofrendo, assim como outras áreas do conhecimento social, influências econômicas, políticas e culturais. Diante dessa evolução, Barros (2007) afirma que a contabilidade se torna um instrumento de processo decisório em nível internacional, e, além disso, ressalta que, como cada país tem suas próprias práticas contábeis, a linguagem não é homogênea em termos internacionais.

Essas práticas contábeis distintas, conforme Otero, Lopes e Lima (2009, p. 2), "são geralmente observadas quando as demonstrações contábeis de uma determinada empresa são preparadas de acordo com as normas contábeis de outro país". De acordo com Fernandes et al. (2010), a necessidade da mobilidade internacional de investimentos, com a procura de melhores alternativas de ganhos, passou a exigir da ciência contábil uma busca por um padrão único, com o objetivo de comparar as demonstrações financeiras de empresas com atuação em diferentes países e de captar recursos nos diversos mercados de capitais.

A partir dessas necessidades dos países e principalmente da busca por informações mais confiáveis e transparentes, tornou-se relevante o processo de convergência contábil internacional, que tem como organismo responsável em nível internacional o IASB - International Accounting Standards, e no Brasil o CPC - Comitê de Pronunciamentos Contábeis, que emite os pronunciamentos baseados nas Normas Internacionais de Contabilidade (IFRS).

Chairas e Radianto (2001) destacam como vantagens da convergência contábil, a maior comparabilidade entre relatórios financeiros; a diminuição dos custos de emissão de diferentes demonstrações; a melhor qualidade das informações e também dos relatórios para a tomada de decisões; e a remoção dos obstáculos aos fluxos internacionais de capital. Deloitte (2008) acrescenta que a adoção das IFRS para os investidores permitirá uma perspectiva comparativa cada vez mais eficaz dos resultados financeiros de empresas. Em se tratando de mercado de capitais, empresas e investidores terão maior facilidade de acesso aos mercados estrangeiros, o que estimulará investimentos e facilitará o fluxo de capital entre os países. Para as empresas, essa adoção possibilitará uma redução de custos, maior coerência das demonstrações contábeis, com a consequente diminuição de erros potenciais da aplicação incorreta das normas.

Contudo, apesar dos benefícios relacionados à convergência contábil, Souza e Coutinho Filho (2004) salientam que, como as Normas Internacionais apresentam divergências em relação às normas brasileiras, o processo de readequação torna-se complexo e dificultoso para a desejada convergência.

A interpretação das Normas Internacionais enquadra-se como uma dessas dificuldades de convergência, devido ao fato de tais normas serem norteadas por princípios, e também por se utilizarem de um alto número de expressões de incerteza, que possibilitam várias interpretações sobre o mesmo assunto. Segundo Castro (2001, p. 2), "estas diferentes interpretações levam à falta de comparabilidade das demonstrações contábeis, o que pode fazer com que a informação contábil perca credibilidade no cenário mundial". Como os pronunciamentos do CPC são 
traduções das Normas Internacionais, eles também possuem expressões de incerteza.

Estudos anteriores, como os de Doupnik e Richter (2003), Chand, Cummings e Patel (2011), Almeida et al. (2008), Doupnik e Riccio (2006), já detectaram que a interpretação dessas expressões pode ser significativamente diferente entre os usuários das normas, tais como contadores de um país para outro, ou de um mesmo país, estudantes chineses comparados aos australianos, estudantes brasileiros de pós-graduação de uma única universidade etc.

Inserido nesse assunto, delimitou-se como tema a interpretação dos Pronunciamentos emitidos pelo Comitê de Pronunciamentos Contábeis, mais especificamente, a percepção dos disscentes sobre as expressões de incerteza contidas em tais pronunciamentos, como sendo um desafio ao entendimento e à aplicação das normas por parte dos elaboradores das demonstrações contábeis.

Tendo em vista a existência de 40 pronunciamentos emitidos pelo CPC, alinhados com as IFRS, optou-se pela utilização daqueles relacionados com instrumentos financeiros, em razão da complexidade da prática com tais instrumentos e também, conforme Oliveira et al. (2004), pelas grandes perdas financeiras que a má utilização desses instrumentos pode ocasionar às empresas.

Para verificar as potenciais diferenças na interpretação das expressões, levou-se em consideração que os alunos do curso de Ciências Contábeis possuem conhecimentos, no mínimo, razoáveis de Contabilidade e que proporcionariam, portanto, uma forma de avaliar como conhecedores de nível intermediário ou mesmo avançado teriam interpretações diferentes sobre os termos relacionados a incertezas.

Assim, o estudo se orienta pela seguinte questão: existem diferenças de percepção entre os discentes do curso de graduação em Ciências Contábeis sobre as expressões de incerteza contidas nos Pronunciamentos emitidos pelo Comitê de Pronunciamentos Contábeis?

Dessa forma, a pesquisa tem como objetivo geral analisar a percepção dos discentes da Universidade Federal de Uberlândia sobre as expressões de incerteza contidas nos Pronunciamentos emitidos pelo Comitê de Pronunciamentos Contábeis. A fim de alcançar esse objetivo, traçaram-se como objetivos específicos os seguintes: i) selecionar um instrumento de coleta de dados, no caso um questionário; ii) enviar o questionário para os grupos selecionados para amostra; iii) verificar a confiabilidade do questionário para a análise proposta; iv) proceder a análises quantitativas, buscando identificar se há diferenças entre a interpretação das expressões de incerteza ou não.

A razão da escolha do tema está relacionada aos futuros praticantes das normas de contabilidade, os discentes atuais, que se inserem num contexto de mudanças e necessitam de atualização profissional para o entendimento de tais normas. Dada a convergência das normas brasileiras para as Normas Internacionais de contabilidade, faz-se necessário analisar como esses alunos se comportam diante da dubiedade de certas expressões e como as interpretam no contexto brasileiro.

Por isso, torna-se relevante, uma vez que diferenças significativas nos julgamentos de estudantes de contabilidade podem gerar sérias implicações para a convergência das normas contábeis na prática. "A falta de consenso sobre o significado das expressões de incerteza contidas nas IFRS torna improvável que estas serão aplicadas de forma consistente, portanto, diferentes interpretações das expressões têm o potencial de minar a credibilidade da convergência 
contábil” (CHAND, CUMMINGS, PATEL, 2011, p. 5).

\section{REFERENCIAL TEÓRICO}

\subsection{O processo de convergência contábil}

O IASC (International Accounting Standards Committee) foi criado, em 1973, pelos organismos profissionais de contabilidade de dez países: França, Alemanha, Canadá, Irlanda, Japão, Austrália, México, Estados Unidos, Reino Unido e Países baixos. Esta entidade foi fundada com o objetivo de formular e publicar pronunciamentos contábeis, para um novo padrão de normas contábeis internacionais que pudesse ser mundialmente aceito. Estes primeiros pronunciamentos foram chamados de IAS - International Accounting Standard (MEIRELLES JUNIOR, 2009).

Em 1997, o IASC criou o SIC (Standing Interpretations Committee), um comitê técnico destinado ao esclarecimento de dúvidas dos usuários referentes às interpretações. Em 2001 o nome desse comitê foi alterado para IFRIC (International Financial Reporting Interpretations Committee), que passou a ser responsável pela publicação de todas interpretações sobre o conjunto de normas internacionais. Atualmente esse comitê é chamado IFRS Interpretations Committee. Ainda em 2001, em substituição ao IASC, foi criado o IASB (International Accounting Standards Board), com sede em Londres e que publica e atualiza as Normas Internacionais de Contabilidade (atualmente, as normas emitidas pelo IASB ${ }^{1}$ são as IFRS International Financial Reporting Standards). Seu compromisso principal é desenvolver um modelo único de normas contábeis, de modo que, na elaboração das demonstrações financeiras, haja transparência e comparabilidade, a fim de atender investidores, analistas, pesquisadores, administradores, ou quaisquer outros usuários interessados nessas demonstrações (MEIRELLES JUNIOR, 2009).

Desde 2001, quase 120 países têm exigido ou permitido o uso do IFRS; as demais economias já estabeleceram linhas de tempo para adotar ou convergir às IFRS em um futuro próximo (IFRS Foundation, 2011).

Partindo para o contexto brasileiro, Nogueira, Reis e Tarifa (2011, p. 4) asseguram que "os esforços para a convergência contábil das normas brasileiras às Normas Internacionais iniciaram-se ainda na década de 90, quando a Comissão de Valores Mobiliários (CVM) promoveu algumas discussões com representantes de entidades de mercado e de órgãos profissionais de ensino". Neste sentido, segundo Reis et al. (2010), no ano de 1999, foi elaborado o anteprojeto de Reformulação da Lei das Sociedades por Ações, que ficou em discussão no Congresso Nacional por muitos anos, o qual continha alterações substanciais em relação aos aspectos contábeis. Como não foram apresentadas conclusões a respeito dessa reformulação, os órgãos reguladores iniciaram então o processo de convergência contábil por meio da regulação tanto profissional quanto das sociedades anônimas de capital aberto.

Assim, em 2005, foi criado o Comitê de Pronunciamentos Contábeis (CPC), que tem

1 A partir de Julho de 2011 a organização passou a ser chamada de IFRS Foundation, porém seu órgão normativo independente continua sendo denominado IASB. 
como objetivo:

o estudo, o preparo e a emissão de Pronunciamentos Técnicos sobre procedimentos de Contabilidade e a divulgação de informações dessa natureza, para permitir a emissão de normas pela entidade reguladora brasileira, visando à centralização e uniformização do seu processo de produção, levando sempre em conta a convergência da Contabilidade Brasileira aos padrões internacionais (CPC, 2011).

O CPC é composto pela Associação Brasileira de Companhias Abertas (ABRASCA), pela Bolsa de Valores de São Paulo (BOVESPA), pelo Conselho Federal de Contabilidade (CFC), pela Associação dos Analistas e Profissionais de Investimento do Mercado de Capitais (APIMEC), pela Fundação Instituto de Pesquisas Contábeis, Atuariais e Financeiras (FIPECAFI) e o pelo Instituto dos Auditores Independentes (IBRACON). Até o momento, o citado órgão já editou 40 pronunciamentos técnicos baseados nas IFRS.

Reis et al. (2010) acrescentam que, com a criação do CPC, muitos reguladores começaram a exigir a preparação e publicação de demonstrações financeiras consolidadas de acordo com as Normas Internacionais de contabilidade a partir de 31/12/2010. O Banco Central do Brasil (BACEN) e a Superintendência de Seguros Privados (SUSEP) já instituíram a exigência da convergência contábil para as entidades de suas alçadas.

O processo de adoção das IFRS ocorreu principalmente por meio da lei 11.638/07, considerada um marco da convergência, pois, alterou dispositivos da lei 6.404/76, que estava em vigor há mais de 30 anos. As leis 11.638/07 e 11.941/09 modificaram algumas das práticas contábeis brasileiras, com alterações na composição dos elementos das demonstrações, nos conceitos e critérios de reconhecimento e mensuração, bem como nas divulgações em notas explicativas (PONTE, 2011).

\subsection{Interpretação das normas internacionais como desafio à convergência}

Como as IFRS estão no idioma inglês, é necessário fazer a tradução para outros idiomas, quando forem aplicadas em outros países. De acordo com Evans (2004), equívocos podem ser cometidos em função da linguagem, em relação à tradução de conceitos contábeis de uma língua para outra, e isso pode afetar a tomada de decisões por usuários, como, investidores, governo, pesquisadores, estudantes de contabilidade etc. Complementando essa afirmação, Almeida et al. (2008) destacam que a terminologia nas IFRS é diferenciada, pois ora uma palavra tem um significado, ora, em outro contexto, possui outro, o que dificulta a tradução.

Portanto, palavras podem ser compreendidas independentemente de conceitos, pois, se algum conceito é incorporado nas tradições de contabilidade de um país, mas que nunca foi conhecido ou aplicado em outro, mesmo que seja traduzido o mais exatamente possível na língua do segundo país, pode não ser entendido (ZEFF, 2007). Além disso, Carsberg (1997, apud CASTRO, 2001, p. 2) já declarava que "os contadores habitam uma espécie de torre de babel, em que não só falam idiomas diferentes, como também interpretam diferentemente os mesmos eventos e transações".

Dantas et al. (2010) afirmam que as normas editadas pelo IASB são baseadas em 
princípios, nas quais em vez da especificação de como promover uma classificação, ou um reconhecimento, mensuração e divulgação de determinado evento econômico, oferecem diretrizes para o julgamento profissional. Nesta mesma linha, Gannon (2007) assinala que, "como a ênfase das Normas Internacionais é dada aos objetivos e princípios, a maneira de redigir os padrões contábeis precisa mudar, pois a aplicação dos novos padrões exigirá mais julgamento, o que implica uma nova maneira de pensar".

Diante dessa nova necessidade, Barth (2006) argumenta que os educadores precisam ensinar os alunos a fazer julgamentos, pois ensinar simplesmente aos alunos as regras existentes e a escrituração pode contribuir para a atração de pessoas erradas para a profissão. A profissão contábil carece de pessoas que estejam dispostas a analisar um contexto de uma norma e fazer algum tipo de julgamento, e não somente daquelas que querem somente seguir regras. Chand, Cummings e Patel (2011) acrescentam que a consistência nos julgamentos pode ser melhorada, oferecendo cursos mais específicos, com casos práticos de interpretação e aplicação das IFRS por parte dos estudantes, em vez da utilização da memorização mecânica dos conteúdos.

Essa ampliação do poder de julgamento conferida aos profissionais de Contabilidade, entretanto, tem sofrido críticas a respeito do poder de facilitar ou induzirà prática do gerenciamento de resultados, pois, de acordo com Baptista (2009), o preparador das demonstrações financeiras, dispondo de novos instrumentos, poderá utilizá-los como veículo de manipulação.

Ainda ponderando sobre o assunto julgamentos, é oportuno lembrar que de acordo com as práticas contábeis brasileiras devem ser pautados no conservadorismo, pois, de acordo com o Hendriksen e Breda (1999, p.175), "os contadores devem divulgar o menor dos vários valores para ativos e receitas e o maior dos vários valores possíveis para passivos e despesas, sendo as despesas reconhecidas mais cedo e receitas reconhecidas mais tarde". Neste sentido Iudicibus, Martins e Gelbcke (2000) ressaltam que o conservadorismo não deve ser confundido com os efeitos da manipulação de resultados, mas considerado como o cuidado e a neutralidade que a Contabilidade precisa ter diante de excessos de entusiasmo e de valorizações pelos responsáveis pela entidade.

Entretanto é necessário destacar que na estrutura conceitual, conservadorismo não faz parte das orientações do IASB, ou seja, não é considerado como característica qualitativa da informação, sendo que um exemplo poderia ser o fato de se trabalhar com valor justo.

\subsection{Expressões de incerteza}

Em relação às Normas Internacionais de contabilidade (IFRS), é notável a existência de várias expressões que, por denotarem incerteza, podem dificultar o entendimento dos usuários. Dentre essas expressões, conforme Teixeira e Silva (2009), Salleh et al. (2011), Doupnik e Riccio (2006), Du e Stevens (2011) e Chand, Cummings e Patel (2011), destacam-se: expected, likely, possible, remote, probable, certain, reasonably, possible, highly probable, reasonable certainty, reasonably possible, virtually certain, reasonable assurance, etc.

Segundo Laswad e Mak (1997, apud Chand, Cummings e Patel, 2011, p. 3), as IFRS contém muitos princípios e expressões incerteza cuja função é orientar as decisões tomadas na prática. Citam como exemplo expressões de incerteza como: "provável", "influência significativa", "controle" e "substancial", que são frequentemente utilizados para denotar 
níveis de probabilidade de prescrever o reconhecimento, mensuração e divulgação de eventos e transações em relatórios financeiros.

De acordo com Teixeira e Silva (2009), quase todas as normas utilizam-se de expressões de incerteza, ou expressões de probabilidade. Em algumas normas, estas expressões são mencionadas em conceitos, o que pode acarretar um impacto indireto sobre a interpretação e aplicabilidade das normas, enquanto, em outras, as expressões estão ligadas ao reconhecimento, à mensuração e à divulgação de critérios, o que pode impactar diretamente na interpretação e aplicação das normas contábeis.

O estudo de Doupnik e Richter (2003) demonstrou que a cultura nacional, bem como a linguagem, podem afetar a probabilidade numérica que os contadores profissionais atribuem às expressões de incerteza. Ainda para esses mesmos autores, a variabilidade na resposta das expressões de incerteza pode ser devido ao significado vago das expressões ou mesmo ao fato de que o significado de termos de probabilidade não é constante entre os indivíduos. Almeida et al. (2008) explicam que as diferenças de percepções em relação às expressões de incerteza podem gerar entendimentos distintos, o que pode acarretar distorções na interpretação destas e, assim, produzir informações diferentes, levando em conta uma mesma base. À medida que essas expressões utilizadas pelas Normas Internacionais são interpretadas por contabilistas e auditores de maneira diferente, e também em diferentes países, a comparabilidade dos relatórios financeiros pode ser prejudicada (DOUPNIK e RICHTER, 2003).

Davidson (1989, apud SALLEH et al., 2011, p. 804) esclarece que "a interpretação de expressões de incerteza está associada a quatro fatores: i) contexto; ii) método utilizado para comunicar a informação ao tomador de decisão; iii) diferenças nos atributos individuais (ex: informações demográficas do indivíduo); e iv) limitações cognitivas dos tomadores de decisão". Assim como nas Normas Internacionais, os pronunciamentos do CPC, por serem baseados nestas, envolvem também um grande número de expressões de incerteza. Algumas delas, traduzidas como "provável", "razoavelmente possível", "altamente provável", "não se espera", "razoavelmente prevista" e "espera", são utilizadas para reconhecer, divulgar ou mensurar determinados eventos nas empresas relacionados, por exemplo, a operações com Instrumentos Financeiros.

A Instrução Normativa da CVM no 235 define instrumento financeiro como "todo contrato que dá origem a um ativo financeiro em uma entidade e a um passivo financeiro ou título representativo do patrimônio em outra entidade" (CVM, 1995). Para Carvalho (1996), um instrumento financeiro resulta de um contrato entre duas ou mais partes dispostas a realizar determinada transação de transferência de recursos. Os instrumentos financeiros se dividem em primários, aqueles resultantes da transação original da companhia decorrentes de compra, venda, emissão, lançamento ou contratação e secundários aqueles que se originam dos instrumentos financeiros primários.

Dantas et al. (2010), citando Lopes, Galdi e Lima (2009), reforçam o impacto que o julgamento profissional apresenta na contabilização de operações com instrumentos financeiros, de modo que se tornam necessárias a apreciação e a decisão acerca, por exemplo, do momento do reconhecimento ou desreconhecimento, da classificação e avaliação, e da identificação da finalidade da operação.

A seguir se apresenta um exemplo utilizando a expressão "não se espera", citada no CPC 38 sobre Reconhecimento e Mensuração de Instrumentos Financeiros. 
Para hedges de transação prevista, o ganho ou a perda cumulativo resultante do instrumento de hedge que se mantém reconhecido como outros resultados abrangentes desde o período em que o hedge era eficaz deve permanecer reconhecido separadamente no patrimônio líquido até que a transação prevista ocorra ou deixe de se esperar que ocorra. [...] Se já não se espera que a transação ocorra, o ganho ou a perda cumulativa que tinha sido reconhecida diretamente no patrimônio líquido deve ser reconhecido no resultado (CPC 38, 2009, item 101, grifo nosso).

A interpretação de uma transação que não se espera que ocorra pode ser afetada pelo perfil do profissional, sendo que aqueles que se mostram mais conservadores para o reconhecimento de uma operação que resulte em um ganho, atribuirão menores probabilidades, enquanto que, se for considerada uma perda, os alunos que atribuírem maiores probabilidades estarão sendo mais conservadores. Assim, dependendo das probabilidades atribuídas à mesma expressão, algumas pessoas poderiam reconhecer o ganho ou a perda no resultado, enquanto outras os reconheceriam separadamente no patrimônio líquido. Esse fato pode gerar um impacto nas informações fornecidas aos stakeholders, já que pode afetar o nível de evidenciação das operações com instrumentos financeiros da entidade.

\section{ASPECTOS METODOLÓGICOS}

Quanto aos objetivos, a pesquisa caracteriza-se como descritiva. Para Beuren (2009), essas pesquisas descrevem aspectos ou comportamentos de uma população que está sendo analisada. Como o trabalho buscou descrever características de discentes, bem como observar, registrar e analisar a percepção destes sobre expressões de incerteza, sem interferência por parte dos pesquisadores, ele se classifica como descritivo. Em relação à abordagem do problema, utilizou-se a pesquisa quantitativa que, no ponto de vista de Richardson (1999, p.70), "caracteriza-se pelo emprego da quantificação tanto nas modalidades de coleta de informações, quanto no tratamento delas por meio de técnicas estatísticas, desde as mais simples [...] às mais complexas". Foi utilizado esse tipo de pesquisa, pois pretendeu-se medir opiniões de um determinado público alvo, por meio de métodos estatísticos.

Quanto aos procedimentos técnicos, recorreu-se, no estudo, ao levantamento, pois apresentou como objetivo a interrogação direta de discentes, por meio de questionários. Segundo Gil (2002, p.30), essas pesquisas se caracterizam:

pela interrogação direta das pessoas cujo comportamento se deseja conhecer. Basicamente, procede-se à solicitação de informações a um grupo significativo de pessoas, amostra acerca do problema estudado, para, em seguida, mediante análise quantitativa através de técnicas estatísticas, obterem-se as conclusões correspondentes aos dados coletados.

Para a realização deste estudo, foram selecionados discentes a partir do $6^{\circ}$ período do curso de graduação em Ciências Contábeis da Universidade Federal de Uberlândia, devido ao fato de a disciplina Contabilidade Internacional ser ministrada a partir deste período. Contudo a inclusão do $10^{\circ}$ período na amostra, o único período que participava da grade curricular antiga, e cujos alunos não cursaram a citada disciplina, justificou-se pelo fato de tais alunos já estarem se formando e, portanto, poderem se deparar com os pronunciamentos do CPC; consequentemente, eles podem se deparar com as expressões de incerteza. Além disso, as suas respostas serviram como base de comparação para os demais períodos, a fim de verificar se existe influência na percepção sobre as expressões, por não terem cursado a disciplina Contabilidade 


\section{Internacional.}

A obtenção dos dados e respostas do público escolhido foi feita a partir da aplicação de um questionário, composto por questões abrangendo o perfil dos respondentes e perguntas sobre as expressões de incerteza. Tal questionário foi elaborado com base em dois outros questionários, que estão disponíveis nos seguintes trabalhos: Almeida et al. (2008) e Doupnik e Riccio (2006).

O questionário, apresentado no Apêndice A, é composto de duas partes distintas. A primeira parte, composta por 13 questões, foi destinada à caracterização do perfil dos respondentes, com dados como atividade profissional e questões específicas sobre a disciplina Contabilidade Internacional. A segunda parte do questionário foi destinada à verificação da percepção dos discentes sobre o percentual atribuído às expressões de incerteza. Para essa parte do questionário foram extraídos sete trechos dos CPC's referentes a Instrumentos Financeiros que continham expressões de incerteza, sendo destacada uma expressão em cada trecho.

Dentre os pronunciamentos sobre Instrumentos Financeiros, CPC 38 (Reconhecimento e Mensuração), CPC 39 (Apresentação) e CPC 40 (Evidenciação), foram escolhidas seis expressões de incerteza, sendo elas as seguintes:"provável","razoavelmente possível", "razoavelmente prevista", "não se espera", "altamente provável" e "espera". A expressão "altamente provável" foi analisada em dois contextos, ou seja, em dois trechos diferentes dos pronunciamentos, sendo que um dos trechos que continham a expressão foi retirado do CPC 38 e o outro do CPC 40. Para a distinção das duas expressões foi utilizado o símbolo (*) quando se referia ao trecho recorte do CPC 40.

Para se chegar à versão final do questionário foram feitas pelo menos três alterações significativas no questionário inicialmente desenvolvido, ou seja, foram desenvolvidos prétestes. Na primeira versão do questionário, após a realização do primeiro pré-teste, identificouse que as expressões de incerteza apresentadas de forma isolada (ou seja, fora do contexto) não estavam permitindo a identificação de diferenças em escalas de probabilidade decorrentes das expressões de incerteza em si. Essa primeira versão foi aplicada a uma amostra de 33 alunos de um curso de pós-graduação (especialização), da área de contabilidade, de uma universidade pública mineira. Pelas respostas obtidas, os percentuais atribuídos foram incompatíveis com a faixa comumente associada a essas expressões, o que pode ser um indício de uma falta de compreensão ou falta de atenção por parte dos respondentes ao preencher o questionário. Essa constatação foi reforçada por meio de entrevistas com outros alunos e anotação de sugestões para melhoria do questionário.

Assim, optou-se por desenvolver a pesquisa com um contexto específico, onde as expressões de incerteza estivessem presentes em frases transcritas dos pronunciamentos, de modo que os discentes poderiam atribuir um percentual de acordo com o trecho recorte do CPC. Foi então desenvolvida uma segunda versão do questionário, que novamente foi avaliada por três discentes de graduação em Ciências Contábeis (que cursavam o último período do curso); suas observações possibilitaram mudanças tanto nos trechos escolhidos quanto na disposição das questões, o que resultou na terceira versão do instrumento de coleta de dados. Foi feito um novo pré-teste com essa terceira versão em uma amostra de 22 alunos, que passou a compor a base de dados da pesquisa, pelo fato de os resultados e comentários realizados após a aplicação do questionário terem se mostrado satisfatórios.

O contato com os discentes foi realizado pessoalmente por meio de visitas às salas de aula, no mês de maio de 2011. O professor de cada uma das turmas selecionadas foi previamente 
consultado para estabelecer o melhor horário de aplicação do questionário. Em cada visita, primeiramente foi exposto o objetivo do estudo com as orientações de preenchimento do questionário, com destaque para a não identificação da pessoa, e em seguida, os questionários foram distribuídos e recolhidos após serem respondidos. A quantidade de alunos matriculados em cada disciplina dos professores escolhidos está disponível na Tabela 1 a seguir.

Tabela 1: Quantidade de alunos por período

\begin{tabular}{cc}
\hline PERÍODO & QUANTIDADE \\
\hline Sexto $\left(6^{\circ}\right)$ & 38 \\
Sétimo $\left(7^{\circ}\right)$ & 40 \\
Oitavo $\left(8^{\circ}\right)$ & 22 \\
Nono $\left(9^{\circ}\right)$ & 26 \\
Décimo $\left(10^{\circ}\right)$ & 48 \\
\hline TOTAL & 174 \\
\hline
\end{tabular}

Assim, de um total de 174 alunos, observou-se que, em média, apenas 4,5\% dos questionários, por período, não foram devolvidos ou foram devolvidos em branco, pois foram obtidos 135 questionários válidos para análise. Na sequência, a fim de se fazer o tratamento quantitativo, foi elaborada uma planilha com a tabulação dos dados, para auxiliar os testes estatísticos. Vale mencionar que, em razão de cursarem períodos diferentes, o nível de conhecimento dos alunos pode estar em diferentes estágios, o que pode também gerar um impacto nos resultados ao se tentar generalizações. Conforme será apresentado na próxima seção, esse fato foi analisado (Apêndice B).

Conforme já destacado anteriormente, para cada uma das expressões de incerteza analisadas no trabalho, foi solicitado que os respondentes atribuíssem um percentual de probabilidade. Como o objetivo da pesquisa é verificar se há diferenças na interpretação dessas expressões, o procedimento estatístico de análise consistiu na comparação dos percentuais médios atribuídos pelos respondentes a cada uma das expressões do questionário.

Para tal comparação, foram empregados dois testes, sendo um paramétrico e o outro não paramétrico, sendo a justificativa para a aplicação de dois testes apresentada ao final deste parágrafo. O teste paramétrico utilizado foi a comparação de médias por meio da Análise da Variância (ANOVA), pois, para Anderson, Sweeney e Williams (2007, p.373), este "procedimento estatístico pode ser usado para determinar se as diferenças observadas nas médias amostrais são suficientemente grandes para a rejeição de $\mathrm{H}_{0}$ ". A contrapartida não paramétrica aplicada foi o Teste de Kruskal-Wallis, que, segundo Webster (2006, p.497), "funciona como uma contrapartida não paramétrica para o delineamento usado na ANOVA". O Teste KruskalWallis também pode ser interpretado como uma extensão do teste Mann-Whitney U quando se deseja comparar duas ou mais populações. Utilizou-se o teste não paramétrico pois supõe-se que a distribuição dos dados experimentais não seja normal, ou que ele não tenha elementos suficientes para poder afirmar que seja. Assim, partiu-se do pressuposto que na dúvida quanto a essa informação, seria interessante também optar pelo uso da estatística não paramétrica. Para todas as análises, foi considerado um nível de significância de 5\%.

Os respondentes foram caracterizados de acordo com os seguintes critérios: i) Período em que o aluno se encontra; ii) Familiaridade com as IFRS; iii) Familiaridade com CPC's; iv) Utilização CPC's; v) Utilização IFRS; vi) Aproveitamento na disciplina Contabilidade Internacional; vii) Opinião sobre os benefícios da convergência contábil; e viii) Opinião sobre Expressões Incerteza e tomada decisão dos usuários internos. Cada um dos critérios citados para caracterização dos respondentes possuía diferentes alternativas (conforme pode ser conferido no Apêndice A), alternativas estas que serviram de base para a realização dos testes estatísticos 
mencionados no parágrafo anterior.

Os testes foram conduzidos tendo como base a seguinte Hipótese Nula $\left(\mathrm{H}_{0}\right)$ : a probabilidade média atribuída à expressão analisada não possui diferença estatisticamente significativa entre os grupos de respondentes analisados; a correspondente Hipótese Alternativa $\left(\mathrm{H}_{1}\right)$ foi: a diferença entre as médias atribuídas à expressão analisada, para os diferentes grupos, é estatisticamente significativa.

\section{ANÁLISE DOS RESULTADOS}

Em uma análise inicial dos 135 questionários respondidos, verificou-se que houve casos com a expressão "altamente provável" com percentual atribuído menor que o da expressão "Provável". Buscando-se garantir maior confiabilidade aos resultados a serem obtidos com este trabalho, tais casos foram excluídos da amostra, somando um total de 31 questionários descartados. Assim, a análise descritiva resultou da avaliação de 104 questionários, o que corresponde a uma taxa de resposta de, aproximadamente, $77 \%$ dos coletados.

A Tabela 2, apresentada a seguir, resume as estatísticas descritivas para todas as variáveis escolhidas e para as expressões de incerteza. Optou-se por utilizar somente as variáveis de segregação nas quais pelo menos uma das expressões de incerteza apresentasse diferença estatisticamente significava entre as interpretações. Assim, de um total de 12 variáveis (critérios de segregação) e, consequentemente 12 análises, foram omitidos os resultados para quatro variáveis: "área de interesse de atuação", "área de atuação", "concursos públicos" e "composição do CPC".

Tabela 2: Estatística descritiva das variáveis

\begin{tabular}{lcccccc}
\hline Variável & N & $\begin{array}{c}\text { Missing } \\
\text { Values }\end{array}$ & Mínimo & Máximo & Média & Desv. Pad. \\
\hline Período & 104 & 0 & 6 & 10 & n.a. & n.a. \\
Area_Interesse & 102 & 2 & n.a. & n.a. & n.a. & n.a. \\
Area_Atuacao & 102 & 2 & n.a. & n.a. & n.a. & n.a. \\
Famil_IFRS & 99 & 5 & n.a. & n.a. & n.a. & n.a. \\
Famil_CPC & 100 & 4 & n.a. & n.a. & n.a. & n.a. \\
Utiliz_IFRS & 103 & 1 & n.a. & n.a. & n.a. & n.a. \\
Utiliz_CPC & 102 & 2 & n.a. & n.a. & n.a. & n.a. \\
Aprov_Intern & 104 & 0 & n.a. & n.a. & n.a. & n.a. \\
Conc_Publicos & 103 & 1 & n.a. & n.a. & n.a. & n.a. \\
Orgaos_CPC & 101 & 3 & n.a. & n.a. & n.a. & n.a. \\
Benef_Converg & 103 & 1 & n.a. & n.a. & n.a. & n.a. \\
Expres_Incert_Interf & 102 & 2 & n.a. & n.a. & n.a. & n.a. \\
Provavel & 100 & 4 & 0,000 & 100,000 & 65,250 & 20,948 \\
Raz_Possivel & 100 & 4 & 10,000 & 90,000 & 43,030 & 17,091 \\
Raz_Prevista & 100 & 4 & 5,000 & 90,000 & 49,210 & 18,270 \\
Não_Espera & 100 & 4 & 0,000 & 90,000 & 18,880 & 19,790 \\
Altam_Prov & 100 & 4 & 20,000 & 100,000 & 84,460 & 16,155 \\
Espera & 100 & 4 & 20,000 & 100,000 & 63,640 & 17,802 \\
Altam_Prov $(*)$ & 100 & 4 & 20,000 & 100,000 & 84,769 & 15,307 \\
\hline Notas: & 4.900
\end{tabular}

Notas: n.a. = não aplicável, em razão das respectivas variáveis não serem escalares.

(*) Expressão analisada no segundo contexto 
De acordo com a Tabela 2, a menor média de probabilidade de ocorrência foi atribuída à expressão "Não se espera". Em contrapartida, a maior média foi atribuída à expressão "Altamente provável (*)". Pode-se observar que as médias atribuídas às expressões "Altamente provável", no primeiro trecho recorte e "Altamente provável (*)" no segundo trecho recorte, se apresentaram muito próximas visualmente; 84,460 e 84,769 respectivamente. Contudo, para confirmar essa proximidade, é necessário que as médias não sejam estatisticamente diferentes, o que foi comprovado por meio de um Teste $t$.

O Apêndice B descreve os resultados obtidos pelo primeiro critério de seleção: período em que o aluno se encontra, e, além disso, o número de alunos em cada período, o percentual médio atribuído às expressões, o desvio padrão desse percentual médio, e os resultados utilizados para os dois testes, sendo o paramétrico, ANOVA, e o não paramétrico, Kruskall-Wallis.

Conforme indica o Apêndice $\mathrm{B}$, a probabilidade média atribuída por alunos de diferentes períodos não foi estatisticamente diferente para as expressões "Razoavelmente possível", "Razoavelmente Prevista" e "Espera", o que denota que, mesmo estando em períodos diferentes, os alunos parecem possuir interpretações similares sobre estas expressões de incerteza, o que pode levar a contabilizações semelhantes de eventos condicionados a elas. Entretanto, é possível observar, que no nível de 5\%, considerando-se o teste paramétrico e o não paramétrico, a diferença foi significativa para as demais expressões: "Não se espera", "Provável" e "Altamente provável" (nos dois contextos).

Observou-se que as menores médias das expressões "Provável” e "Altamente provável" foram atribuídas pelo $10^{\circ}$ período. Os resultados parecem evidenciar que, para a expressão "Provável", os alunos do décimo período tendem a ser menos conservadores ao reconhecerem uma perda, enquanto que os alunos que cursam o $7^{\circ}$ período tendem a ser mais conservadores, o que se verifica pelas maiores probabilidades atribuídas a essa expressão. As considerações de Davidson (1989, apud SALLEH et al., 2011), de que atributos individuais ou diferenças cognitivas afetam a interpretação das expressões de incerteza, parece ser aplicável também a este estudo.

O segundo critério foi a familiaridade com as Normas Internacionais, descrito na tabela do Apêndice C, cujas colunas são as mesmas apresentadas pelo Apêndice anterior. De acordo com esse Apêndice, a probabilidade média atribuída por alunos que possuem diferentes níveis de familiaridade com as IFRS foi estatisticamente diferente para a expressão "Provável", tanto pela ANOVA, quanto pelo Teste Kruskall-Wallis. Para as expressões "Altamente Provável" e "Altamente Provável (*)", a diferença foi significativa pelo teste paramétrico, mas não significativa pelo outro teste, o que deve ser observado atentamente, devido ao fato de o teste não paramétrico ser considerado mais confiável, para este caso. Vale destacar que as maiores probabilidades de ocorrência dessas três expressões foram dos discentes que marcaram a opção "familiar".

A próxima análise, descrita no Apêndice D, consistiu em aplicar como critério a familiaridade com os pronunciamentos emitidos pelo CPC. Alinhado ao resultado do critério utilizado no Apêndice anterior, as mesmas três expressões, "Provável", "Altamente Provável" e "Altamente Provável (*)" apresentaram probabilidades médias estatisticamente diferentes entre os respondentes, desta vez, somente pelo teste paramétrico. As menores probabilidades de ocorrência, para as três expressões, foram dadas pelos discentes que se dizem "não familiares" com os Pronunciamentos emitidos pelo CPC. Contudo, essa diferença deve ser analisada com cautela, pois não foi reconhecida pelo teste não paramétrico. 
Considerando-se como critério de seleção a utilização dos Pronunciamentos emitidos pelo CPC, a tabela disponível no Apêndice E resume os resultados obtidos. De acordo com os dados, podem-se observar diferenças significantes por parte dos testes ANOVA e KruskallWallis para as expressões "Provável" e "Altamente provável", esta apresentada nos dois contextos (trechos diferentes). O Apêndice mostra também que aqueles que não utilizaram os pronunciamentos, foram os que atribuíram menores médias a essas expressões. Conforme apontado anteriormente, aqueles que atribuíram menores percentuais à expressão "Provável" podem contabilizar um evento relacionado à perda, de maneira menos conservadora.

O critério para segregação escolhido para a tabela do Apêndice F foi a utilização das Normas Contábeis Internacionais no cotidiano dos alunos. Assim como o critério de seleção do Apêndice anterior (utilização dos Pronunciamentos emitidos pelo CPC), para a variável, utilização das Normas Internacionais, observou-se diferenças significativas tanto para o teste paramétrico, quanto para o outro teste, e para as mesmas expressões: "Provável", "Altamente provável" e "Altamente provável (*)". Notou-se, também, que quem não utiliza as Normas Internacionais atribuiu menores percentuais de probabilidade, estando esses resultados de acordo com o verificado no Apêndice E.

O próximo critério, presente no Apêndice G, levou em consideração o nível de aproveitamento apresentado na disciplina de contabilidade internacional. A tabela contida nesse Apêndice aponta que a expressão "Não se espera" apresentou um p-valor abaixo de 0,05 somente para o teste não paramétrico, indicando que as médias dos grupos são estatisticamente diferentes. Os discentes que obtiveram aproveitamento ótimo na disciplina foram os que atribuíram as menores probabilidades de ocorrência. Levando-se em conta o texto em que essa expressão está inserida, os resultados parecem indicar que, caso seja uma operação que resulte em um ganho, os alunos demonstraram-se mais conservadores para o seu reconhecimento; contudo, se for considerada uma perda, eles se mostraram menos conservadores.

As demais expressões, "Provável" e "Altamente provável” nos dois trechos, também apresentaram diferenças significativas, mas não apenas pelo teste não paramétrico, e sim pelos dois. Verificou-se que, para essas expressões, os alunos que tiveram aproveitamento "muito bom" na matéria foram os responsáveis pelas maiores médias.

A penúltima variável empregada para segregação, demonstrada no Apêndice $H$, foram os benefícios da convergência para os relatórios contábeis. Conforme exposto pela tabela desse Apêndice, as expressões "Razoavelmente Possível" e "Altamente provável", esta analisada nos dois trechos diferentes, expuseram diferenças significativas, e apenas pelo teste paramétrico. Assim, conforme comentado anteriormente, essa divergência deve ser analisada com cautela, pois, pelo teste Kruskall-Wallis, não houve diferença significativa no nível de 5\%. Pode-se considerar, então, que as médias das demais expressões se apresentaram muito próximas. Observa-se uma maior probabilidade atribuída pelos alunos que acreditam fortemente nos benefícios da convergência contábil.

Na última análise realizada, aplicou-se o critério expressões de incerteza e seu potencial de interferência na tomada de decisão dos usuários internos. Visualizaram-se diferenças significativas pelo Teste Kruskall-Wallis para a expressão "Provável", e pela ANOVA para a expressão "Altamente provável (*)". Alinhado ao critério anterior, o grupo que acredita fortemente que as expressões de incerteza têm o potencial de interferir nas tomadas de decisões dos usuários internos foi o que atribuiu maiores probabilidades de ocorrência. Os resultados foram obtidos pelo Apêndice I. 
Verificou-se por meio das análises, que a utilização de um contexto específico, isto é, considerando as expressões dentro de trechos dos pronunciamentos contábeis, pode ter possibilitado um maior entendimento por parte dos discentes quanto ao percentual a ser aplicado a cada expressão de incerteza, o que, consequentemente, propiciou uma maior taxa de respondentes, além de dados mais adequados para o teste da hipótese proposta. Essa vantagem do uso de um contexto específico pode ser comprovada por meio da pesquisa de Teixeira e Silva (2009), em que parte dos questionários voltaram incompletos, o que, segundo os auditores, amostra da pesquisa, foi justificado pela ausência de um contexto (expressões estavam isoladas).

Destaca-se que, conforme registrado pelos resultados comentados, as expressões de incerteza contidas nos pronunciamentos contábeis possuem diferentes formas de interpretação, para diferentes pessoas, o que permitiu a rejeição da hipótese nula adotada na pesquisa, em que a probabilidade média atribuída à expressão analisada não possui diferença estatisticamente significativa entre os grupos de respondentes analisados; e portando aceitação da Hipótese Alternativa $\left(\mathrm{H}_{1}\right)$.

As expressões que mais se destacaram nessa interpretação, as quais podem ser tomadas de maneira diferenciada, foram "Provável”, “Altamente Provável”. Doupnik e Riccio (2006), em seu estudo, também encontraram diferenças significativas entre contadores brasileiros e americanos quanto à interpretação de "Provável", quando utilizado nos seguintes contextos: reconhecimento de receitas, custos de desenvolvimento, divulgação de ativos contingentes etc.

Ainda sobre essa expressão, Teixeira e Silva (2009) salientam que "Razoavelmente possível" e "Provável" estão entre as expressões mais pesquisadas nos estudos, e acrescentam ainda que a literatura parece concordar que o uso de expressões de probabilidade, em particular, "Provável" não é apropriado para expressar probabilidades, e que sua interpretação inconsistente pode afetar a aplicação correta das normas contábeis. No mesmo sentido, Davidson (1989, apud DOUPNIK e RICHTER, 2003, p. 17) sugeriu que, como a expressão "Razoavelmente possível" é percebida como semelhante à expressão "Provável", ela poderia ser substituída por "Às vezes", a fim de transmitir um nível de probabilidade como sendo uma média entre as expressões "Remoto"e "Provável".

Assim sendo, as diversas formas de entendimento de uma mesma expressão levam a uma reflexão quanto a algum tipo de contabilização ou evidenciação, pois, caso esteja condicionada a uma das expressões analisadas, com diferença significativa de interpretação, poderia ser feita de maneira divergente pelos usuários das normas. Essa divergência pode ser um dos fatores que, conforme já comentado na introdução e no referencial teórico, impactaria a comparabilidade dos relatórios contábeis de diferentes empresas, o que apresenta, inclusive, um entrave ao alcance dos objetivos propostos pela implementação das Normas Internacionais de Contabilidade.

\section{CONSIDERAÇÕES FINAIS}

Esta pesquisa buscou analisar a percepção dos discentes da Universidade Federal de Uberlândia sobre as expressões de incerteza contidas nos Pronunciamentos emitidos pelo Comitê de Pronunciamentos Contábeis. Foram selecionadas seis expressões de incerteza dos 
pronunciamentos referentes a Instrumentos Financeiros e dispostos em contexto específico (trechos transcritos) num questionário. Foram utilizados os pronunciamentos sobre Instrumentos Financeiros em razão de as operações com tais instrumentos terem se tornado um tema polêmico, devido à complexidade com que se apresentam nas normas e ao grande impacto que causam nos resultados das entidades, o que justificou a escolha de tais CPC. Os questionários foram distribuídos aos alunos do $6^{\circ}$ ao $10^{\circ}$ período do Curso de Ciências Contábeis, para que atribuíssem uma probabilidade de ocorrência a cada uma das expressões.

Empregaram-se como critério de segregação doze variáveis, a fim de comparar essas probabilidades médias e, para a análise estatística, a ANOVA como teste paramétrico, e o Teste Kruskall-Wallis, como não paramétrico. Vale destacar que, aquelas variáveis extraídas no início da análise ("área de interesse de atuação", "área de atuação", "concursos públicos" e “composição do CPC") não revelaram diferenças significativas entre os grupos.

A pesquisa apontou que apenas as expressões "Razoavelmente prevista" e "Espera" não apresentaram diferenças na percepção sobre elas. As demais expressões "Razoavelmente Possível", "Não se espera", "Provável", "Altamente Provável" e "Altamente Provável (*)" exibiram diferenças significativas no nível de 5\%, em relação a determinadas variáveis de segregação, sobressaindo as expressões "Altamente Provável" e "Provável”. É interessante observar que esta última expressão é a que mais se repete nos Pronunciamentos Contábeis, o que foi verificado mediante uma pesquisa em todos os CPC, por meio de uma planilha eletrônica, em que eram contadas quantas vezes cada expressão se repetia em cada CPC. Em alguns pronunciamentos "Provável" não aparecia, mas no geral foi a expressão que mais se repetiu em quantidade.

Após as análises, de modo geral, os resultados sugeriram que existem diferenças de percepção quanto às expressões de incerteza contidas nos Pronunciamentos do CPC. Tais resultados indicam a rejeição da hipótese $\mathrm{H}_{0}$ testada na pesquisa, e, portanto aceitação da Hipótese Alternativa $\left(\mathrm{H}_{1}\right)$, em que a diferença entre as médias atribuídas à expressão analisada, para os diferentes grupos, é estatisticamente significativa. Esses resultados se alinham a pesquisas anteriores, como as de Doupnik e Richter (2003), Almeida et al. (2008) e Chand, Cummings e Patel (2011), e fornecem indícios, especialmente para o contexto brasileiro, sobre potenciais barreiras que podem afetar a convergência das normas contábeis em nível internacional.

Conclui-se, portanto, que a imprecisão em relação às expressões de incerteza pode acarretar interpretações distintas de um mesmo evento, influenciando, assim, nas tomadas de decisões dos elaboradores das demonstrações contábeis e na comparabilidade destas. Além disso, como o novo padrão contábil utiliza-se de uma maior subjetividade em relação aos BR- GAAP anteriores, os profissionais contábeis passam a ter um maior poder de julgamento, o que pode propiciar novas análises, em pesquisas futuras, envolvendo o gerenciamento de resultados.

As vantagens relacionadas com a convergência contábil (CHAIRAS e RADIANTO, 2001; DELOITTE, 2008) podem, assim, ter certo limite, mesmo que sensível, em razão de diferentes percepções que diferentes usuários das normas contábeis possuem sobre uma mesma expressão que envolve incerteza (mesmo sendo apresentado o contexto que envolve essa expressão). O processo de tradução das normas de contabilidade, apontado por alguns autores como um dos desafios para a convergência contábil (SOUZA e COUTINHO FILHO, 2004; EVANS, 2004; ZEFF, 2007), tem seu efeito como barreira à convergência ampliado (ou, pelo menos, complementado) quando estão envolvidas as expressões de incerteza, pois, além de se poder contar com divergências nas traduções, após traduzidas, ainda pode haver divergências 
de interpretações das normas.

Esses resultados apontam, para os órgãos reguladores, a importância do aprimoramento das normas contábeis a fim de que se faça menos uso desse tipo de expressão, bem como as defina melhor, de modo que sejam mais precisas, para que haja aumento da compreensibilidade das transações e maior comparabilidade dos relatórios. Para os investidores, esses resultados podem mostrar que, mesmo com normas equivalentes entre diferentes mercados de capitais, há ainda a possibilidade de serem observados resultados diferentes (ou níveis diferentes de informações) decorrentes da aplicação das normas, e não das operações (ou da performance) da empresa, em si.

Tem-se como limitações desta pesquisa o público alvo, com uma amostra somente de discentes e de uma única universidade. Outra limitação está no fato de a pesquisa analisar a percepção sobre as expressões de incerteza somente nos Pronunciamentos referentes a Instrumentos Financeiros, pois existem expressões de incerteza em outros pronunciamentos. Além disso, após a coleta dos dados, foi identificado que: i) o questionário pode não ter deixado claro que as "Normas Internacionais de Contabilidade" são os International Financial Reporting Standards (IFRSs) do IASB; ii) para a questão 12, não foi comentado qual a opção feita pela entidade para a data de transição, se teria sido conforme a norma "Práticas Contábeis, Mudanças nas Estimativas Contábeis e Correção de Erros" ou se teria sido pela Lei n. ${ }^{\circ}$ 6.404/76; e iii) a questão 23 pode ter ficado redundante, pois entende-se que, em tomadas de decisões, a incerteza é um dos componentes do processo.

Por fim, a utilização de questionário para mensurar as expressões de incerteza também seria um limite, pois parte-se do pressuposto de que os respondentes o preencheram de acordo com sua interpretação, e não aleatoriamente. Recomenda-se a realização de pesquisas futuras envolvendo outros pronunciamentos contábeis, outras expressões de incerteza, alunos de outras Universidades brasileiras e também com profissionais que já estejam atuando com os pronunciamentos do CPC.

\section{REFERÊNCIAS BIBLIOGRÁFICAS}

ALMEIDA, M. D et al.. Análise da percepção sobre expressões de incerteza presentes nas Normas Internacionais de contabilidade. Revista UnB Contábil, Brasília, v. 11, n. 1-2, p.240259, jan./dez. 2008.

ANDERSON, D. R., SWEENEY, D. J. e WILLIAMS, T. A. Estatística Aplicada à Administração e Economia. 2 ed. São Paulo: Cengage Learning, 2007. 616 p.

BAPTISTA, E. M. B. Ganhos em transparência versus novos instrumentos de manipulação: o paradoxo das modificações trazidas pela lei $\mathrm{n}^{0}$ 11.638. RAE - Revista de administração de empresas. São Paulo, v. 49, n. 2, p. 234-239, abr./jun. 2009.

BARROS, L. P. S. A importância da harmonização das normas contábeis para o aumento da transparência na evidenciação das demonstrações contábeis consolidadas aos usuários internacionais. In: CONVENÇÂOO DE CONTABILIDADE DE MINAS GERAIS, VI, 2007, Belo Horizonte. Anais... Belo Horizonte: CRC-MG, 2007.

BARTH, M. E. Global Financial Reporting: How Does the U.S. Fit In? The Saxe Lectures in Accounting, out. 2006. Disponível em: <http://newman.baruch.cuny.edu/digital/saxe/ saxe_2006/barth_06.htm>. Acesso em: 31 mai. 2011. 
BEUREN, I. M. Como elaborar trabalhos monográficos em contabilidade: teoria e prática. 3 ed. São Paulo: Atlas, 2009. 82p.

CARSBERG, S. B. Uniformizando as normas contábeis ao redor do mundo. Gazeta Mercantil, "Marstering Management", n.2, p.19-21, set. 1997.

CARVAlHO, L. N. G. Uma Contribuição à Auditoria do risco dos derivativos. 1996. P. Tese. (Doutorado em Contabilidade) - Faculdade de Economia, Administração e Contabilidade, Departamento de Contabilidade e Atuária, Universidade de São Paulo, São Paulo, 1996.

CASTRO, M. L. Uma Contribuição ao Estudo da Harmonização das Normas Contábeis na Era da Globalização. In: SEMINÁRIO USP DE CONTABILIDADE, 1, 2001, São Paulo. Anais... São Paulo: 2001.

CHAIRAS, I. Y.; RADIANTO, W. R. D. Accounting Harmonization in ASEAN: the process, benefits and obstacles. 2001. 140 f. Master Thesis, International Accounting and Finance, Göteborg University, 2001.

CHAND, P.; CUMMINGS, L.; PATEL, C. The Effect of Accounting Education and National Culture on Accounting Judgments: A Comparative Study of Anglo-Celtic and Chinese Culture. Disponível em: < $\underline{w w w . s s r n} . c o m>$. Acesso em: 31 mai. 2011.

CPC - Comitê de Pronunciamentos Contábeis. Home / Conheça o CPC / Criação e Objetivo. Disponível em: <http://www.cpc.org.br/>. Acesso em: 22 jul. 2011.

CPC-38 - Pronunciamento Técnico CPC - 38: Instrumentos Financeiros: Reconhecimento e Mensuração. Aprovado em 02 de outubro de 2009.Disponível em: <http://www.cpc.org.br/>. Acesso em: 22 jul. 2011.

CPC-39 - Pronunciamento Técnico CPC-39: Instrumentos Financeiros: Apresentação. Aprovado em 02 de outubro de 2009. Disponível em: <http://www.cpc.org.br/>. Acesso em: 22 jul. 2011.

CPC-40 - Pronunciamento Técnico CPC-40: Instrumentos Financeiros: Evidenciação. Aprovado em 02 de outubro de 2009. Disponível em: http://www.cpc.org.br/>. Acesso em: 22 jul. 2011.

CVM - Comissão de Valores Mobiliários. Instrução $\mathbf{n}^{0}$ 235, de 23 de março de 1995. Dispõe sobre a divulgação, em nota explicativa, do valor de mercado dos instrumentos financeiros, reconhecidos ou não nas demonstrações financeiras das companhias abertas e dá outras providências. Disponível em: <http://www.cvm.gov.br/>. Acesso em: 20 jun. 2011.

DANTAS, J. A. et al. Normatização contábil baseada em princípios ou em regras? Benefícios, custos, oportunidades e riscos. RCO - Revista de Contabilidade e Organizações. FEA-RP/USP, v. 4, n. 9, p. 3-29, mai-ago 2010.

DAVIDSON, R.A., Accounting for Contingencies: A Comparison of U.S. and Canadian Terminology. Proceedings of the 1989 Canadian Academic Accounting Association Conference. 1989.

DELOITTE T. T.. O Brasil na convergência: um guia prático para a adoção do IFRS. 2008. Disponível em: <www.iasplus.com>. Acesso em: 06 jul. 2011.

DOUPNIK, T. S.; RICHTER, M. Interpretation of uncertainty expressions: a cross-national study. Accounting, Organizations and Society, Elsevier, v. 28(1), p. 15-35, jan. 2003.

DOUPNIK, T. S.; RICCIO, E. L. The influence of conservatism and secrecy on the interpretation of verbal probability expressions in the Anglo and Latin cultural areas. The International 
Journal of Accounting, v. 41(3), p. 237-261, 2006.

DU, N.; STEVENS, K. Numeric-to-verbal translation of probability expressions in SFAS 5. Managerial Auditing Journal, Emerald Group Publishing Limited, v. 26, n. 3, p. 248-262, 2011.

EVANS. L. Language, translation and the problem of international accounting communication. Accounting, Auditing \& Accountability Journal, Emerald Group Publishing Limited, v. 17, n. 2, p. 210-248, 2004.

FERNANDES, B. V. R. et al. Análise da percepção dos docentes dos cursos de graduação em Ciências contábeis do Brasil quanto ao processo de Convergência às Normas Internacionais de contabilidade aplicadas no Brasil. In: CONGRESSO ANPCONT - Associação Nacional dos Programas de Pós-Graduação em Ciências Contábeis, IV, 2010, Natal/RN. Anais... Natal: ANPCONT, 2010. p. 1-16.

FEITOSA, A. A globalização da economia e a necessidade de Harmonização contábil. In: CONGRESO INTERNACIONAL DE COSTOS, VII, 2001, León (España). Anais...León: Institut International de Coûst, 2001. p. 1-16.

GANNON, S. J. International Financial Reporting Standards - Mudança de Paradigma na Divulgação das Informações Financeiras. Wall Street Lawyer, v. 11, n. 7, p. 1-6. jul. 2007.

GIL, A. C. Como elaborar projetos de pesquisa. 4 ed. São Paulo: Atlas, 2002. 159 p.

HENDRIKSEN, E. S.; BREDA, M. F. V. Teoria da Contabilidade. Tradução de Antonio Zoratto Sanvicente. 5 ed, São Paulo: Atlas, 1999. 552 p.

IFRS FOUDATION. - International Financial Reporting Standard Foundation. About us / Frequently Asked Questions / IFRS's around the world. Who We Are And What We Do. Disponível em: <www.iasb.org>. Acesso em: 22 jul. 2011.

IUDÍCIBUS, S. Teoria da contabilidade. 6 ed. São Paulo: Atlas, 2000. 336 p.

IUDÍCIBUS, S. MARTINS, E. GELBCKE, E. R. Manual de Contabilidade das Sociedades por Ações: aplicável às demais sociedades. 5 ed., São Paulo: Atlas, 2000.

LASWAD, F.; MAK, Y. T. Interpretations of probability expressions by New Zealand standards setters. Accounting Horizons, v. 11, n. 4, p. 16-23, dec. 1997.

LOPES, A. B.; GALDI, F. C.; LIMA, I. S. Manual de Contabilidade e Tributação de Instrumentos Financeiros e Derivativos: IAS 39, IAS 32, IFRS 7, CPC 14, Minutas do CPC 38, 39 e 40, Normas da CVM, do BACEN e da Receita Federal do Brasil. São Paulo: Atlas, 2009.

MEIRELLES JUNIOR, J. C. Harmonização das Normas Internacionais de contabilidade.In: SEGET - SIMPÓSIO DE EXCELÊNCIA EM GESTÃO E TECNOLOGIA, VII, 2009, Resende. Anais... Resende: Associação Educacional Dom Bosco, 2009. p. 1-12.

NOGUEIRA, D. R.; REIS, L. G.; TARIFA, M. R. Disclosure do Ativo Imobilizado: Análise das Práticas pelas empresas do Novo Mercado Considerando o CPC 27. In: CONGRESSO DE CONTABILIDADE E AUDITORIA, XIII, 2011, Porto. Anais... Porto: Associação dos Institutos Superiores de Contabilidade e Administração, 2011. p. 1-15.

OLIVEIRA, M. C. et al. Estudo da contabilização e evidenciação de derivativos pelas Instituições Financeiras brasileiras. In: CONGRESSO USP DE CONTROLADORIAE CONTABILIDADE, 4, 2004, São Paulo. Anais... São Paulo: Faculdade de Economia, Administração e Contabilidade da USP, Departamento de Contabilidade e Atuária da FEA/USP, 2004. p. 1-15. 
OTERO, J. P; LOPES, S. C. O; LIMA, I. G. Harmonização contábil internacional. In: CONGRESSO VIRTUAL BRASILEIRO DE ADMINISTRAÇÃO - CONVIBRA, VI, 2009, São Paulo. Anais... São Paulo: CONVIBRA, 2009. p. 1-12.

PONTE, V. M. R. et al. Impactos de alterações nas práticas contábeis nos indicadores financeiros das empresas brasileiras. In: CONGRESSOUSPDECONTROLADORIAECONTABILIDADE, 11, 2011, São Paulo. Anais... São Paulo: Faculdade de Economia, Administração e Contabilidade da USP, Departamento de Contabilidade e Atuária da FEA/USP, 2011. p. 1-16.

REIS, L. G. et al. O Processo de Convergência às Normas Internacionais de Contabilidade: uma análise sob a perspectiva dos discentes de Ciências Contábeis. In: CONVENÇÃO ESTADUAL DOS CONTABILISTAS, XV, 2010, Cascavel. Anais... Cascavel: Conselho Regional de Contabilidade do Paraná - CRCPR, 2010. p. 1-9.

RICHARDSON, R. J. Pesquisa social: métodos e técnicas. 3 ed. São Paulo: São Paulo: Atlas, 1999. $334 \mathrm{p}$.

SALLEH, S. M. et al. The Interpretation of "In Context" Verbal Probability Expressions Used in International Accounting Standards: a Comparison of English and Chinese Students Studying at English Speaking Universities. In: NEW ORLEANS INTERNATIONAL ACADEMIC CONFERENCE, I, 2011, New Orleans Anais... New Orleans: The Clute Institute, 2011. p. $1-13$.

SOUZA, A. A. S; COUTINHO FILHO, F. B. Harmonização internacional: um estudo sobre as dificuldades de convergência das normas contábeis brasileiras em relação às Normas Internacionais de contabilidade (IFRS). In: CONGRESSO USP DE CONTROLADORIA E CONTABILIDADE, 4, 2004, São Paulo. Anais...São Paulo: Faculdade de Economia, Administração e Contabilidade da USP, Departamento de Contabilidade e Atuária da FEA/ USP, 2004. p. 1-15.

TEIXEIRA, C. SILVA, A. F. The Interpretation of Verbal Probability Expressions Used in the IAS/IFRS: Some Portuguese Evidence. Revista de Estudos Politécnicos, Barcelos. v. VII, n.12, p. 57-73, ago. 2009.

WEBSTER, A. L. Estatística Aplicada à Administração e Economia. São Paulo: McGraw-Hill, 2006.

ZEFF, S. A. Some obstacles to global financial reporting comparability and convergence at a high level of quality. The British Accounting Review. Elsevier, v. 4, n. 4, p. 290-302, dez. 2007. 


\section{Apêndice A: Questionário utilizado na pesquisa}

\section{Questionário}

Este questionário faz parte de um Trabalho de Conclusão do Curso de Ciências Contábeis da UFU. Solicito sua colaboração, agradecendo-lhe antecipadamente. O objetivo da pesquisa é analisar a percepção sobre as expressões de incerteza contidas nos Pronunciamentos emitidos pelo Comitê de Pronunciamentos Contábeis. Não é necessário identificação. O tempo médio previsto para o seu preenchimento é de 05 minutos.

1a PARTE - Por favor, responda às seguintes questões para o desenvolvimento do perfil dos respondentes.

OBS: Marque apenas 01 alternativa para cada questão.

01 - Você trabalha na área contábil? Há quanto tempo?

02 - Sua principal área de interesse para atuação é?

Auditoria
Outra Tributária $\quad \square$ Controladoria $\square$ Contabilidade Societária

03 - Em que área profissional você atua?

Consultoria
Não Trabalho

05 - Qual seu grau de familiaridade com os Pronunciamentos emitidos pelo CPC?

$\square$ muito familiar $\square$ familiar $\square$ pouco familiar $\square$ não familiar

06 - Qual a intensidade de utilização das Normas Contábeis Internacionais em seu cotidiano?

$\square$ frequentemente $\square$ às vezes $\square$ não utilizo

07 - Qual a intensidade de utilização dos Pronunciamentos emitidos pelo CPC em seu cotidiano?

$\square$ frequentemente $\square$ às vezes $\square$ não utilizo

08 - Qual o órgão responsável pela emissão das normas contábeis em nível internacional?

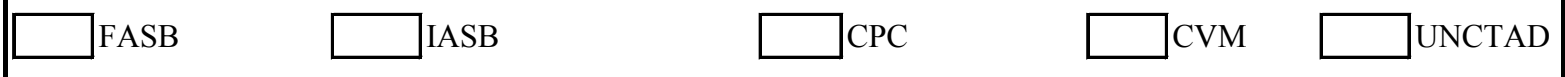

9 - Qual foi o aproveitamento da disciplina Contabilidade Internacional para sua vida acadêmica e profissional?

$\square$ regular $\quad \square$ bom $\quad \square$ muito bom $\square$ ótimo $\square$ não cursei

10 - Você pretende prestar concursos públicos nos próximos meses?

$\square$ não pretendo $\square$ pretendo, e irei estudar $\square$ pretendo, e já estou estudando para isso

11 - Sobre os órgaos que compõem o Comitê de Pronunciamentos contábeis, marque a alternativa incorreta:

$\square$ Fipecafi $\square$ Ibracon $\square$ Apimec $\square$ Bovespa $\square$ CVM

12 - A Cia. Alfa elaborou suas demonstrações contábeis conforme as IFRS em 31/12/2010. Nesse caso, qual foi a data utilizada para o preparo de seu Balanço Patrimonial de Abertura?
$\square 01 / 01 / 2010$.
$31 / 12 / 2009$.
$01 / 01 / 2009$.
$31 / 12 / 2010$

13 - Para você, a convergência contábil para um único padrão trará benefícios para os usuários destes relatórios?

$\square$ não acredito $\square$ acredito $\square$ acredito fortemente 
$2^{\text {a }}$ PARTE - Nesta parte, estão dispostos alguns trechos retirados/adaptados dos CPC's 38 e 40 sobre Instrumentos Financeiros. As expressões destacadas são a própria condição para realização do evento. Sendo assim, por favor indique, em sua opinião, a escala de probabilidade (em percentual) de ocorrência que melhor corresponda às expressões abaixo.

14 - Considera-se como parte das evidências de que um ativo financeiro tenha perda no valor recuperável quando torna-se provável que o devedor vá entrar em processo de falência.

Neste contexto, na sua opinião, "provável" corresponde a

uma probabilidade aproximada de qual percentual?

15 - A entidade deve divulgar uma análise de sensibilidade para cada tipo de risco de mercado aos quais ela esteja exposta ao fim do período contábil, mostrando como o resultado e o patrimônio líquido seriam afetados pelas mudanças no risco que sejam razoavelmente possíveis naquela data.

Neste contexto, na sua opinião, "razoavelmente possíveis" corresponde a uma probabilidade aproximada de qual percentual?

16 - Se a entidade tiver vendido ou reclassificado, antes do seu vencimento, uma quantia significante de "investimentos mantidos até o vencimento", ela não deve mais classificar nenhum ativo financeiro como mantido até o vencimento, a não ser que a venda ou a reclassificação não tenha podido ser razoavelmente prevista pela entidade.

Neste contexto, na sua opinião, "razoavelmente prevista" corresponde a uma probabilidade aproximada de qual percentual?

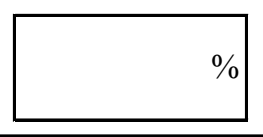

17 - Se já não se espera que uma transação que foi objeto de hedge ocorra, o ganho ou a perda cumulativa que tinha sido reconhecida diretamente no patrimônio líquido deve ser reconhecido no resultado.

Neste contexto, na sua opinião, "não se espera" corresponde a

uma probabilidade aproximada de qual percentual?

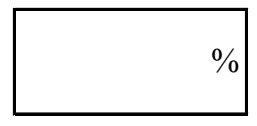

18 - Um objeto de hedge pode ser um ativo ou passivo reconhecido, um compromisso firme não reconhecido, uma transação prevista altamente provável ou um investimento líquido em operação no exterior.

Neste contexto, na sua opinião, "altamente provável" corresponde a

uma probabilidade aproximada de qual percentual?

19 - Se a entidade tiver reclassificado um instrumento financeiro da categoria de disponível para a venda para outra categoria, ela deve evidenciar os montantes estimados dos fluxos de caixa que espera recuperar, na data da reclassificação do ativo financeiro.

Neste contexto, na sua opinião, "espera" corresponde a

uma probabilidade aproximada de qual percentual?

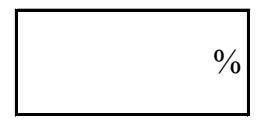

20 - Para hedges de fluxo de caixa, a entidade deve divulgar o montante que tenha sido removido do patrimônio líquido durante o período e incluído no custo inicial ou outro valor contábil de ativo não financeiro ou passivo não financeiro cuja aquisição ou incorrência tenha sido um hedge de operação prevista e altame nte provável.

Neste contexto, na sua opinião, "altamente provável" corresponde a uma probabilidade aproximada de qual percentual?

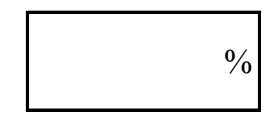

21 - Você acredita que as expressões de incerteza têm o potencial de interferir nas tomadas de decisões? não acredito $\square$ acredito acredito fortemente 
Apêndice B: Resultados da ANOVA e do Kruskal-Wallis para a variável de critério Período

\begin{tabular}{|c|c|c|c|c|c|c|c|c|c|}
\hline $\begin{array}{l}\text { Express são de } \\
\text { Incerteza }\end{array}$ & $\begin{array}{l}\text { Período em que o } \\
\text { aluno se encontra }\end{array}$ & $\mathbf{N}$ & Média & $\begin{array}{l}\text { Desv. } \\
\text { Pad. }\end{array}$ & $\mathbf{F}$ & $\begin{array}{l}\text { Sig. } \\
\text { (F) }\end{array}$ & C.S. & d.f. & $\begin{array}{l}\text { Sig. } \\
\text { (C.S.) }\end{array}$ \\
\hline \multirow{6}{*}{ Raz_Possível } & 6 & 24 & 42,625 & 15,511 & \multirow{6}{*}{1,549} & \multirow{6}{*}{0,194} & \multirow{6}{*}{5,651} & \multirow{6}{*}{4} & \multirow{6}{*}{0,227} \\
\hline & 7 & 21 & 36,429 & 12,956 & & & & & \\
\hline & 8 & 14 & 48,571 & 20,327 & & & & & \\
\hline & 9 & 16 & 41,375 & 16,939 & & & & & \\
\hline & 10 & 25 & 46,920 & 18,910 & & & & & \\
\hline & Total & 100 & 43,030 & 17,091 & & & & & \\
\hline \multirow{6}{*}{ Raz_Prevista } & 6 & 24 & 47,625 & 20,112 & \multirow{6}{*}{1,742} & \multirow{6}{*}{0,147} & \multirow{6}{*}{5,545} & \multirow{6}{*}{4} & \multirow{6}{*}{0,236} \\
\hline & 7 & 21 & 44,048 & 14,800 & & & & & \\
\hline & 8 & 14 & 58,214 & 20,344 & & & & & \\
\hline & 9 & 16 & 45,375 & 20,337 & & & & & \\
\hline & 10 & 25 & 52,480 & 15,163 & & & & & \\
\hline & Total & 100 & 49,210 & 18,270 & & & & & \\
\hline \multirow{6}{*}{ Espera } & 6 & 24 & 64,875 & 18,044 & \multirow{6}{*}{1,280} & \multirow{6}{*}{0,283} & \multirow{6}{*}{4,120} & \multirow{6}{*}{4} & \multirow{6}{*}{0,390} \\
\hline & 7 & 21 & 68,810 & 16,949 & & & & & \\
\hline & 8 & 14 & 55,714 & 19,000 & & & & & \\
\hline & 9 & 16 & 60,938 & 19,851 & & & & & \\
\hline & 10 & 25 & 64,280 & 15,720 & & & & & \\
\hline & Total & 100 & 63,640 & 17,802 & & & & & \\
\hline \multirow{6}{*}{ Não_Espera } & 6 & 24 & 14,500 & 17,300 & \multirow{6}{*}{2,929} & \multirow{6}{*}{0,025} & \multirow{6}{*}{12,696} & \multirow{6}{*}{4} & \\
\hline & 7 & 21 & 9,429 & 8,975 & & & & & \\
\hline & 8 & 14 & 21,786 & 19,376 & & & & & 0013 \\
\hline & 9 & 16 & 23,188 & 29,517 & & & & & 0,013 \\
\hline & 10 & 25 & 26,640 & 18,341 & & & & & \\
\hline & Total & 100 & 18,880 & 19,790 & & & & & \\
\hline & 6 & 24 & 71,750 & 21,549 & & & & & \\
\hline & 7 & 21 & 74,048 & 14,804 & & & & & \\
\hline Prováyel & 8 & 14 & 59,643 & 15,250 & 3407 & 0010 & 13443 & 4 & 0009 \\
\hline Provavel & 9 & 16 & 64,438 & 20,938 & 3,491 & 0,010 & 13,443 & 4 & 0,009 \\
\hline & 10 & 25 & 55,280 & 23,457 & & & & & \\
\hline & Total & 100 & 65,250 & 20,948 & & & & & \\
\hline & 6 & 24 & 88,375 & 14,246 & & & & & \\
\hline & 7 & 21 & 90,905 & 7,245 & & & & & \\
\hline A ltam Proy & 8 & 14 & 82,143 & 13,828 & 2327 & 0013 & 13070 & 4 & 0011 \\
\hline Altam_Prov & 9 & 16 & 85,563 & 19,089 & $3,3<1$ & 0,013 & $13,0 / 9$ & 4 & 0,011 \\
\hline & 10 & 25 & 75,880 & 19,359 & & & & & \\
\hline & Total & 100 & 84,460 & 16,155 & & & & & \\
\hline & 6 & 24 & 87,954 & 13,430 & & & & & \\
\hline & 7 & 21 & 91,429 & 5,211 & & & & & \\
\hline Altam_Prov & 8 & 14 & 83,929 & 12,431 & 057 & 0020 & & & 026 \\
\hline (*) & 9 & 16 & 83,875 & 19,304 & 3,057 & 0,020 & 11,040 & 4 & 0,026 \\
\hline & 10 & 25 & 77,160 & 18,551 & & & & & \\
\hline & Total & 100 & 84,769 & 15,307 & & & & & \\
\hline
\end{tabular}

Notas: $\mathrm{F}=$ estatística para a ANOVA; Sig. $(\mathrm{F})=$ Significância para a estatística $\mathrm{F}$, referente à ANOVA; C.S.= Chi-Square, estatística para o Teste Kruskal-Wallis; d.f.= graus de liberdade para a estatística de C.S., referente ao Teste Kruskal-Wallis; Sig. (C.S.)= Significância para a estatís tica C.S., referente ao Teste Kruskal-Wallis.

(*) Expressão analisada no segundo contexto 
Apêndice C: Resultados da ANOVA e do Kruskal-Wallis para a variável de critério Familiaridade com as IFRS

\begin{tabular}{|c|c|c|c|c|c|c|c|c|c|}
\hline $\begin{array}{l}\text { Express são de } \\
\text { Incerteza }\end{array}$ & $\begin{array}{c}\text { Familiaridade com } \\
\text { as IFRS }\end{array}$ & $\mathbf{N}$ & Média & $\begin{array}{l}\text { Desv. } \\
\text { Pad. }\end{array}$ & $\mathbf{F}$ & $\begin{array}{l}\text { Sig. } \\
\text { (F) }\end{array}$ & C.S. & d.f. & $\begin{array}{l}\text { Sig. } \\
\text { (C.S.) }\end{array}$ \\
\hline \multirow{5}{*}{ Raz_Possível } & Não Familiar & 5 & 42,000 & 30,537 & & & & & \\
\hline & Pouco Familiar & 58 & 42,810 & 16,184 & & & & & \\
\hline & Familiar & 33 & 44,545 & 16,787 & 0,383 & 0,766 & 1,314 & 3 & 0,726 \\
\hline & Muito familar & 4 & 35,000 & 17,321 & & & & & \\
\hline & Total & 100 & 43,030 & 17,091 & & & & & \\
\hline \multirow{5}{*}{ Raz_Prevista } & Não Familiar & 5 & 43,000 & 36,844 & & & & & \\
\hline & Pouco Familiar & 58 & 48,724 & 15,553 & & & & & \\
\hline & Familiar & 33 & 51,818 & 19,954 & 0,603 & 0,615 & 1,918 & 3 & 0,590 \\
\hline & Muito familar & 4 & 42,500 & 12,583 & & & & & \\
\hline & Total & 100 & 49,210 & 18,270 & & & & & \\
\hline \multirow{5}{*}{ Espera } & Não Familiar & 5 & 68,000 & 24,900 & & & & & \\
\hline & Pouco Familiar & 58 & 61,793 & 17,174 & & & & & \\
\hline & Familiar & 33 & 65,455 & 18,471 & 0,585 & 0,626 & 2,781 & 3 & 0,427 \\
\hline & Muito familar & 4 & 70,000 & 14,142 & & & & & \\
\hline & Total & 100 & 63,640 & 17,802 & & & & & \\
\hline \multirow{5}{*}{ Não_Espera } & Não Familiar & 5 & 11,000 & 11,402 & & & & & \\
\hline & Pouco Familiar & 58 & 22,293 & 20,748 & & & & & \\
\hline & Familiar & 33 & 14,212 & 18,171 & 1,477 & 0,226 & 4,179 & 3 & 0,243 \\
\hline & Muito familar & 4 & 17,750 & 21,915 & & & & & \\
\hline & Total & 100 & 18,880 & 19,790 & & & & & \\
\hline \multirow{5}{*}{ Provável } & Não Familiar & 5 & 42,000 & 25,884 & & & & & \\
\hline & Pouco Familiar & 58 & 61,638 & 21,292 & & & & & \\
\hline & Familiar & 33 & 74,818 & 15,587 & 5,636 & 0,001 & 13,490 & 3 & 0,004 \\
\hline & Muito familar & 4 & 67,750 & 14,614 & & & & & \\
\hline & Total & 100 & 65,250 & 20,948 & & & & & \\
\hline \multirow{5}{*}{ Altam_Prov } & Não Familiar & 5 & 69,000 & 29,665 & & & & & \\
\hline & Pouco Familiar & 58 & 82,707 & 17,459 & & & & & \\
\hline & Familiar & 33 & 89,848 & 8,182 & 3,174 & 0,028 & 3,940 & 3 & 0,268 \\
\hline & Muito familar & 4 & 84,750 & 12,527 & & & & & \\
\hline & Total & 100 & 84,460 & 16,155 & & & & & \\
\hline \multirow{5}{*}{ Altam_Prov $(*)$} & Não Familiar & 5 & 72,600 & 30,803 & & & & & \\
\hline & Pouco Familiar & 58 & 82,309 & 16,714 & & & & & \\
\hline & Familiar & 33 & 90,485 & 5,461 & 3,396 & 0,021 & 3,453 & 3 & 0,327 \\
\hline & Muito familar & 4 & 88,500 & 9,950 & & & & & \\
\hline & Total & 100 & 84,769 & 15,307 & & & & & \\
\hline
\end{tabular}

Notas: $\mathrm{F}=$ estatística para a ANOVA; Sig. $(\mathrm{F})=$ Significância para a estatística $\mathrm{F}$, referente à ANOVA; C.S.= Chi-Square, estatística para o Teste Kruskal-Wallis; d.f.= graus de liberdade para a estatística de C.S., referente ao Teste Kruskal-Wallis; Sig. (C.S.)= Significância para a estatística C.S., referente ao Teste Kruskal-Wallis .

(*) Expressão analisada no segundo contexto 
Apêndice D: Resultados da ANOVA e do Kruskal-Wallis para a variável de critério Familiaridade com os CPC's

\begin{tabular}{|c|c|c|c|c|c|c|c|c|c|}
\hline $\begin{array}{l}\text { Express são de } \\
\text { Incerteza }\end{array}$ & $\begin{array}{c}\text { Familiaridade com } \\
\text { CPC's }\end{array}$ & $\mathbf{N}$ & Média & $\begin{array}{l}\text { Desv. } \\
\text { Pad. }\end{array}$ & $\mathbf{F}$ & $\begin{array}{l}\text { Sig. } \\
\text { (F) }\end{array}$ & C.S. & d.f. & $\begin{array}{l}\text { Sig. } \\
\text { (C.S.) }\end{array}$ \\
\hline \multirow{5}{*}{ Raz_Possível } & Não Familiar & 4 & 48,750 & 26,575 & \multirow{5}{*}{0,496} & \multirow{5}{*}{0,686} & \multirow{5}{*}{1,154} & \multirow{5}{*}{3} & \multirow{5}{*}{0,764} \\
\hline & Pouco Familiar & 53 & 44,377 & 17,107 & & & & & \\
\hline & Familiar & 40 & 40,950 & 16,899 & & & & & \\
\hline & Muito familar & 3 & 39,333 & 1,155 & & & & & \\
\hline & Total & 100 & 43,030 & 17,091 & & & & & \\
\hline \multirow{5}{*}{ Raz_Prevista } & Não Familiar & 4 & 50,000 & 33,417 & \multirow{5}{*}{0,083} & \multirow{5}{*}{0,969} & \multirow{5}{*}{0,711} & \multirow{5}{*}{3} & \multirow{5}{*}{0,871} \\
\hline & Pouco Familiar & 53 & 48,623 & 15,809 & & & & & \\
\hline & Familiar & 40 & 49,575 & 20,464 & & & & & \\
\hline & Muito familar & 3 & 53,667 & 11,846 & & & & & \\
\hline & Total & 100 & 49,210 & 18,270 & & & & & \\
\hline \multirow{5}{*}{ Espera } & Não Familiar & 4 & 50,000 & 14,142 & \multirow{5}{*}{2,466} & \multirow{5}{*}{0,067} & \multirow{5}{*}{6,862} & \multirow{5}{*}{3} & \multirow{5}{*}{0,076} \\
\hline & Pouco Familiar & 53 & 60,698 & 16,562 & & & & & \\
\hline & Familiar & 40 & 68,675 & 18,810 & & & & & \\
\hline & Muito familar & 3 & 66,667 & 15,275 & & & & & \\
\hline & Total & 100 & 63,640 & 17,802 & & & & & \\
\hline \multirow{5}{*}{ Não_Espera } & Não Familiar & 4 & 30,000 & 23,094 & \multirow{5}{*}{0,997} & \multirow{5}{*}{0,398} & \multirow{5}{*}{4,371} & \multirow{5}{*}{3} & \multirow{5}{*}{0,224} \\
\hline & Pouco Familiar & 53 & 20,717 & 18,780 & & & & & \\
\hline & Familiar & 40 & 15,350 & 20,369 & & & & & \\
\hline & Muito familar & 3 & 18,667 & 27,209 & & & & & \\
\hline & Total & 100 & 18,880 & 19,790 & & & & & \\
\hline \multirow{5}{*}{ Provável } & Não Familiar & 4 & 37,500 & 37,749 & \multirow{5}{*}{3,598} & & & & \\
\hline & Pouco Familiar & 53 & 63,245 & 19,322 & & & & & \\
\hline & Familiar & 40 & 70,325 & 19,718 & & 0,016 & 7,044 & 3 & 0,071 \\
\hline & Muito familar & 3 & 70,000 & 10,000 & & & & & \\
\hline & Total & 100 & 65,250 & 20,948 & & & & & \\
\hline & Não Familiar & 4 & 63,750 & 35,444 & & & & & \\
\hline & Pouco Familiar & 53 & 82,321 & 17,291 & & & & & \\
\hline Altam_Prov & Familiar & 40 & 88,925 & 9,445 & 3,981 & 0,010 & 3,748 & 3 & 0,290 \\
\hline & Muito familar & 3 & 90,333 & 9,609 & & & & & \\
\hline & Total & 100 & 84,460 & 16,155 & & & & & \\
\hline & Não Familiar & 4 & 63,250 & 34,865 & & & & & \\
\hline & Pouco Familiar & 53 & 82,094 & 16,550 & & & & & \\
\hline (*) & Familiar & 40 & 90,223 & 6,522 & 5,596 & 0,001 & 4,890 & 3 & 0,180 \\
\hline & Muito familar & 3 & 88,000 & 9,849 & & & & & \\
\hline & Total & 100 & 84,769 & 15,307 & & & & & \\
\hline
\end{tabular}

Notas: $\mathrm{F}=$ estatística para a ANOVA; Sig. $(\mathrm{F})=$ Significância para a estatística $\mathrm{F}$, referente à ANOVA; C.S.= Chi-Square, estatística para o Teste Kruskal-Wallis; d.f.= graus de liberdade para a estatística de C.S., referente ao Teste Kruskal-Wallis; Sig. (C.S.)= Significância para a estatística C.S., referente ao Teste Kruskal-Wallis.

(*) Expressão analisada no segundo contexto 
Apêndice E: Resultados da ANOVA e do Kruskal-Wallis para a variável de critério Utilização dos CPC's

\begin{tabular}{|c|c|c|c|c|c|c|c|c|c|}
\hline $\begin{array}{l}\text { Express ão de } \\
\text { Incerteza }\end{array}$ & Utilização CPC's & $\mathbf{N}$ & Média & $\begin{array}{l}\text { Desv. } \\
\text { Pad. }\end{array}$ & $\mathbf{F}$ & $\begin{array}{l}\text { Sig. } \\
\text { (F) }\end{array}$ & C.S. & d.f. & $\begin{array}{l}\text { Sig. } \\
\text { (C.S.) }\end{array}$ \\
\hline \multirow{4}{*}{ Raz_Possível } & Não Utilizo & 38 & 44,000 & 16,867 & \multirow{4}{*}{0,222} & \multirow{4}{*}{0,801} & \multirow{4}{*}{0,615} & \multirow{4}{*}{2} & \multirow{4}{*}{0,735} \\
\hline & Às vezes & 48 & 42,625 & 18,188 & & & & & \\
\hline & Frequentemente & 13 & 40,385 & 14,210 & & & & & \\
\hline & Total & 99 & 42,859 & 17,092 & & & & & \\
\hline \multirow{4}{*}{ Raz_Prevista } & Não Utilizo & 38 & 49,658 & 17,701 & \multirow{4}{*}{1,542} & \multirow{4}{*}{0,219} & \multirow{4}{*}{3,674} & \multirow{4}{*}{2} & \multirow{4}{*}{0,159} \\
\hline & Às vezes & 48 & 50,396 & 17,911 & & & & & \\
\hline & Frequentemente & 13 & 40,769 & 18,467 & & & & & \\
\hline & Total & 99 & 48,848 & 18,000 & & & & & \\
\hline \multirow{4}{*}{ Espera } & Não Utilizo & 38 & 61,368 & 18,847 & \multirow{4}{*}{0,920} & \multirow{4}{*}{0,402} & \multirow{4}{*}{1,430} & \multirow{4}{*}{2} & \multirow{4}{*}{0,489} \\
\hline & Às vezes & 48 & 66,083 & 16,953 & & & & & \\
\hline & Frequentemente & 13 & 60,769 & 18,467 & & & & & \\
\hline & Total & 99 & 63,576 & 17,881 & & & & & \\
\hline \multirow{4}{*}{ Não_Espera } & Não Utilizo & 38 & 21,526 & 19,542 & \multirow{4}{*}{2,446} & \multirow{4}{*}{0,092} & \multirow{4}{*}{2,877} & \multirow{4}{*}{2} & \multirow{4}{*}{0,237} \\
\hline & Às vezes & 48 & 14,938 & 15,100 & & & & & \\
\hline & Frequentemente & 13 & 27,000 & 31,324 & & & & & \\
\hline & Total & 99 & 19,051 & 19,817 & & & & & \\
\hline \multirow{4}{*}{ Provável } & Não Utilizo & 38 & 58,974 & 23,967 & \multirow{4}{*}{3,181} & \multirow{4}{*}{0,046} & \multirow{4}{*}{5,076} & \multirow{4}{*}{2} & \multirow{4}{*}{0,079} \\
\hline & Às vezes & 48 & 67,271 & 18,418 & & & & & \\
\hline & Frequentemente & 13 & 73,846 & 15,021 & & & & & \\
\hline & Total & 99 & 64,949 & 20,837 & & & & & \\
\hline & Não Utilizo & 38 & 77,184 & 20,498 & & & & & \\
\hline Altam Prov & Às vezes & 48 & 88,917 & 10,008 & 6714 & 0002 & 8880 & 2 & 0012 \\
\hline Altam_Prov & Frequentemente & 13 & 88,231 & 13,700 & $0, / 14$ & 0,002 & 8,880 & 2 & 0,012 \\
\hline & Total & 99 & 84,323 & 16,179 & & & & & \\
\hline & Não Utilizo & 38 & 77,921 & 19,712 & & & & & \\
\hline Altam Proy (*) & Às vezes & 48 & 88,873 & 9,129 & 6596 & 0.002 & 7582 & & 023 \\
\hline Altam_Prov(") & Frequentemente & 13 & 88,615 & 12,725 & 6,596 & 0,002 & 7,582 & 2 & 0,023 \\
\hline & Total & 99 & 84,635 & 15,326 & & & & & \\
\hline
\end{tabular}

Notas: $\mathrm{F}=$ estatística para a ANOVA; Sig. $(\mathrm{F})=$ Significância para a estatística $\mathrm{F}$, referente à ANOVA; C.S.= Chi-Square, estatística para o Teste Kruskal-Wallis; d.f.= graus de liberdade para a estatística de C.S., referente ao Teste Kruskal-Wallis; Sig. (C.S.)= Significância para a estatística C.S., referente ao Teste Kruskal-Wallis.

(*) Expressão analisada no segundo contexto 
Apêndice F: Resultados da ANOVA e do Kruskal-Wallis para a variável de critério Utilização das IFRS

\begin{tabular}{|c|c|c|c|c|c|c|c|c|c|}
\hline $\begin{array}{l}\text { Express ão de } \\
\text { Incerteza }\end{array}$ & Utilização IFRS & $\mathbf{N}$ & Média & $\begin{array}{c}\text { Desv. } \\
\text { Pad. }\end{array}$ & $\mathbf{F}$ & $\begin{array}{c}\text { Sig. } \\
\text { (F) }\end{array}$ & C.S. & d.f. & $\begin{array}{l}\text { Sig. } \\
\text { (C.S.) }\end{array}$ \\
\hline \multirow{4}{*}{ Raz_Possível } & Não Utilizo & 56 & 43,268 & 17,781 & \multirow{4}{*}{0,573} & \multirow{4}{*}{0,566} & \multirow{4}{*}{1,124} & \multirow{4}{*}{2} & \multirow{4}{*}{0,570} \\
\hline & Às vezes & 37 & 43,919 & 16,463 & & & & & \\
\hline & Frequentemente & 7 & 36,429 & 15,469 & & & & & \\
\hline & Total & 100 & 43,030 & 17,091 & & & & & \\
\hline \multirow{4}{*}{ Raz_Prevista } & Não Utilizo & 56 & 49,839 & 19,403 & \multirow{4}{*}{0,163} & \multirow{4}{*}{0,850} & \multirow{4}{*}{0,433} & \multirow{4}{*}{2} & \multirow{4}{*}{0,805} \\
\hline & Às vezes & 37 & 48,919 & 17,043 & & & & & \\
\hline & Frequentemente & 7 & 45,714 & 17,182 & & & & & \\
\hline & Total & 100 & 49,210 & 18,270 & & & & & \\
\hline \multirow{4}{*}{ Espera } & Não Utilizo & 56 & 62,661 & 18,794 & \multirow{4}{*}{0,256} & \multirow{4}{*}{0,775} & \multirow{4}{*}{0,503} & \multirow{4}{*}{2} & \multirow{4}{*}{0,778} \\
\hline & Às vezes & 37 & 64,459 & 16,699 & & & & & \\
\hline & Frequentemente & 7 & 67,143 & 17,043 & & & & & \\
\hline & Total & 100 & 63,640 & 17,802 & & & & & \\
\hline \multirow{4}{*}{ Não_Espera } & Não Utilizo & 56 & 19,607 & 18,542 & \multirow{4}{*}{0,084} & \multirow{4}{*}{0,919} & \multirow{4}{*}{0,392} & \multirow{4}{*}{2} & \multirow{4}{*}{0,822} \\
\hline & Às vezes & 37 & 17,946 & 22,385 & & & & & \\
\hline & Frequentemente & 7 & 18,000 & 17,117 & & & & & \\
\hline & Total & 100 & 18,880 & 19,790 & & & & & \\
\hline \multirow{4}{*}{ Provável } & Não Utilizo & 56 & 58,464 & 22,273 & \multirow{4}{*}{10,575} & \multirow{4}{*}{0,000} & \multirow{4}{*}{19,555} & \multirow{4}{*}{2} & \multirow{4}{*}{0,000} \\
\hline & Às vezes & 37 & 76,757 & 14,054 & & & & & \\
\hline & Frequentemente & 7 & 58,714 & 14,545 & & & & & \\
\hline & Total & 100 & 65,250 & 20,948 & & & & & \\
\hline & Não Utilizo & 56 & 80,804 & 18,508 & & & & & \\
\hline Altam Proy & Às vezes & 37 & 90,324 & 9,496 & 4.163 & 0.018 & 6,402 & 2 & 0.041 \\
\hline Altam_Prov & Frequentemente & 7 & 82,714 & 16,879 & 4,103 & 0,018 & 0,402 & 2 & 0,041 \\
\hline & Total & 100 & 84,460 & 16,155 & & & & & \\
\hline & Não Utilizo & 56 & 81,123 & 17,648 & & & & & \\
\hline Altam Proy (*) & Às vezes & 37 & 90,000 & 8,631 & 4014 & 0021 & 6072 & 2 & 0.048 \\
\hline & Frequentemente & 7 & 86,286 & 16,378 & & & 0,012 & & \\
\hline & Total & 100 & 84,769 & 15,307 & & & & & \\
\hline
\end{tabular}

Notas: $\mathrm{F}=$ estatística para a ANOVA; Sig. $(\mathrm{F})=$ Significância para a estatística $\mathrm{F}$, referente à ANOVA; C.S.= Chi-Square, estatística para o Teste Kruskal-Wallis; d.f.= graus de liberdade para a estatística de C.S., referente ao Teste Kruskal-Wallis; Sig. (C.S.)= Significância para a estatística C.S., referente ao (*) Expressão analis ada no segundo contexto 
Apêndice G: Resultados da ANOVA e do Kruskal-Wallis para a variável de critério Aproveitamento na disciplina Contabilidade Internacional

\begin{tabular}{|c|c|c|c|c|c|c|c|c|c|}
\hline $\begin{array}{l}\text { Express ão de } \\
\text { Incerteza }\end{array}$ & $\begin{array}{c}\text { Aproveitamento } \\
\text { Contab. Internac. }\end{array}$ & $\mathbf{N}$ & Média & $\begin{array}{l}\text { Desv. } \\
\text { Pad. }\end{array}$ & $\mathbf{F}$ & $\begin{array}{l}\text { Sig. } \\
\text { (F) }\end{array}$ & C.S. & d.f. & $\begin{array}{l}\text { Sig. } \\
\text { (C.S.) }\end{array}$ \\
\hline \multirow{6}{*}{ Raz_Possível } & não curs ei & 26 & 47,038 & 18,537 & \multirow{6}{*}{1,047} & \multirow{6}{*}{0,387} & \multirow{6}{*}{3,878} & \multirow{6}{*}{4} & \multirow{6}{*}{0,423} \\
\hline & regular & 20 & 46,250 & 19,660 & & & & & \\
\hline & bom & 30 & 40,000 & 15,322 & & & & & \\
\hline & muito bom & 17 & 40,882 & 13,720 & & & & & \\
\hline & ótimo & 7 & 37,143 & 17,995 & & & & & \\
\hline & Total & 100 & 43,030 & 17,091 & & & & & \\
\hline \multirow{6}{*}{ Raz_Prevista } & não cursei & 26 & 51,231 & 16,165 & \multirow{6}{*}{1,024} & \multirow{6}{*}{0,399} & \multirow{6}{*}{4,819} & \multirow{6}{*}{4} & \multirow{6}{*}{0,306} \\
\hline & regular & 20 & 51,750 & 21,538 & & & & & \\
\hline & bom & 30 & 43,967 & 15,912 & & & & & \\
\hline & muito bom & 17 & 53,235 & 20,987 & & & & & \\
\hline & ótimo & 7 & 47,143 & 17,995 & & & & & \\
\hline & Total & 100 & 49,210 & 18,270 & & & & & \\
\hline \multirow{6}{*}{ Espera } & não cursei & 26 & 65,269 & 16,208 & \multirow{6}{*}{0,342} & \multirow{6}{*}{0,849} & \multirow{6}{*}{1,303} & \multirow{6}{*}{4} & \multirow{6}{*}{0,861} \\
\hline & regular & 20 & 59,750 & 20,678 & & & & & \\
\hline & bom & 30 & 63,567 & 19,676 & & & & & \\
\hline & muito bom & 17 & 64,706 & 12,180 & & & & & \\
\hline & ótimo & 7 & 66,429 & 20,959 & & & & & \\
\hline & Total & 100 & 63,640 & 17,802 & & & & & \\
\hline \multirow{6}{*}{ Não_Espera } & não curs ei & 26 & 26,385 & 18,018 & \multirow{6}{*}{2,135} & \multirow{6}{*}{0,082} & \multirow{6}{*}{12,053} & \multirow{6}{*}{4} & \\
\hline & regular & 20 & 20,750 & 24,294 & & & & & \\
\hline & bom & 30 & 17,700 & 20,780 & & & & & 0017 \\
\hline & muito bom & 17 & 10,882 & 13,564 & & & & & 0,011 \\
\hline & ótimo & 7 & 10,143 & 11,408 & & & & & \\
\hline & Total & 100 & 18,880 & 19,790 & & & & & \\
\hline & não cursei & 26 & 56,615 & 23,970 & & & & & \\
\hline & regular & 20 & 57,500 & 19,702 & & & & & \\
\hline Provável & bom & 30 & 68,100 & 17,036 & 5374 & 0001 & 20085 & 4 & 0000 \\
\hline & muito bom & 17 & 81,706 & 9,225 & & & & & 0,000 \\
\hline & ótimo & 7 & 67,286 & 25,526 & & & & & \\
\hline & Total & 100 & 65,250 & 20,948 & & & & & \\
\hline & não curs ei & 26 & 76,423 & 19,169 & & & & & \\
\hline & regular & 20 & 78,650 & 21,958 & & & & & \\
\hline Altam Proy & bom & 30 & 89,333 & 7,004 & 5120 & 0001 & 15020 & 1 & 0005 \\
\hline Altam_Prov & muito bom & 17 & 93,706 & 5,785 & 5,128 & 0,001 & 15,039 & 4 & 0,005 \\
\hline & ótimo & 7 & 87,571 & 12,555 & & & & & \\
\hline & Total & 100 & 84,460 & 16,155 & & & & & \\
\hline & não cursei & 26 & 77,654 & 18,350 & & & & & \\
\hline & regular & 20 & 78,600 & 21,387 & & & & & \\
\hline Altam Droy (*) & bom & 30 & 89,897 & 6,008 & 4020 & 0001 & 12170 & 4 & 0010 \\
\hline Altam_Prov (*) & muito bom & 17 & 92,647 & 5,522 & 4,922 & 0,001 & 13,170 & 4 & 0,010 \\
\hline & ótimo & 7 & 87,714 & 9,742 & & & & & \\
\hline & Total & 100 & 84,769 & 15,307 & & & & & \\
\hline
\end{tabular}

Notas: $\mathrm{F}=$ estatística para a ANOVA; Sig. $(\mathrm{F})=$ Significância para a estatística $\mathrm{F}$, referente à ANOVA; C.S.= Chi-Square, estatística para o Teste Kruskal-Wallis; d.f.= graus de liberdade para a estatística de C.S., referente ao Teste Kruskal-Wallis; Sig. (C.S.)= Significância para a estatística C.S., referente ao Teste Kruskal-Wallis.

(*) Expressão analis ada no segundo contexto 
Apêndice H: Resultados da ANOVA e do Kruskal-Wallis para a variável de critério Benefícios da Convergência

\begin{tabular}{|c|c|c|c|c|c|c|c|c|c|}
\hline $\begin{array}{l}\text { Express ão de } \\
\text { Incerteza }\end{array}$ & $\begin{array}{c}\text { Benefícios } \\
\text { Convergência }\end{array}$ & $\mathbf{N}$ & Média & $\begin{array}{l}\text { Desv. } \\
\text { Pad. }\end{array}$ & $\mathbf{F}$ & $\begin{array}{l}\text { Sig. } \\
\text { (F) }\end{array}$ & C.S. & d.f. & $\begin{array}{l}\text { Sig. } \\
\text { (C.S.) }\end{array}$ \\
\hline \multirow{2}{*}{ Raz_Possível } & acredito & 61 & 41,852 & 14,848 & \multirow{2}{*}{4,600} & \multirow{2}{*}{0,034} & \multirow{2}{*}{0,044} & \multirow{2}{*}{1} & \multirow{2}{*}{0,834} \\
\hline & acredito fortemente & 37 & 44,189 & 20,430 & & & & & \\
\hline \multirow{2}{*}{ Raz_Prevista } & acredito & 61 & 47,705 & 16,775 & \multirow{2}{*}{1,467} & \multirow{2}{*}{0,229} & \multirow{2}{*}{0,150} & \multirow{2}{*}{1} & \multirow{2}{*}{0,699} \\
\hline & acredito fortemente & 37 & 50,838 & 20,395 & & & & & \\
\hline \multirow{2}{*}{ Espera } & acredito & 61 & 63,967 & 19,137 & \multirow{2}{*}{1,873} & \multirow{2}{*}{0,174} & \multirow{2}{*}{0,001} & \multirow{2}{*}{1} & \multirow{2}{*}{0,982} \\
\hline & acredito fortemente & 37 & 63,568 & 15,980 & & & & & \\
\hline \multirow{2}{*}{ Não_Espera } & acredito & 61 & 18,016 & 17,818 & \multirow{2}{*}{0,004} & \multirow{2}{*}{0,950} & \multirow{2}{*}{0,001} & \multirow{2}{*}{1} & \multirow{2}{*}{0,979} \\
\hline & acredito fortemente & 37 & 18,622 & 22,199 & & & & & \\
\hline \multirow{2}{*}{ Provável } & acredito & 61 & 63,082 & 21,788 & \multirow{2}{*}{1,205} & \multirow{2}{*}{0,275} & \multirow{2}{*}{2,970} & \multirow{2}{*}{1} & \multirow{2}{*}{0,085} \\
\hline & acredito fortemente & 37 & 70,189 & 18,481 & & & & & \\
\hline \multirow{2}{*}{ Altam_Prov } & acredito & 61 & 82,705 & 17,713 & \multirow{2}{*}{17,162} & \multirow{2}{*}{0,000} & \multirow{2}{*}{1,623} & \multirow[t]{2}{*}{1} & \multirow{2}{*}{0,203} \\
\hline & acredito fortemente & 37 & 89,622 & 7,829 & & & & & \\
\hline \multirow{2}{*}{ Altam_Prov $(*)$} & acredito & 61 & 82,736 & 17,162 & & & & 1 & \\
\hline & acredito fortemente & 37 & 89,865 & 7,843 & J & 0,000 & & 1 & $J 6$ \\
\hline
\end{tabular}

Notas: $\mathrm{F}=$ es tatís tica para a ANOVA; Sig. $(\mathrm{F})=$ Significância para a estatística $\mathrm{F}$, referente à ANOVA; C.S.= Chi-Square, estatística para o Teste Kruskal-Wallis; d.f.= graus de liberdade para a estatística de C.S., referente ao Teste Kruskal-Wallis; Sig. (C.S.)= Significância para a estatística C.S., referente ao Teste Kruskal-Wallis.

(*) Expressão analisada no segundo contexto

Apêndice I: Resultados da ANOVA e do Kruskal-Wallis para a variável de critério Expressões de incerteza e tomada de decisão

\begin{tabular}{|c|c|c|c|c|c|c|c|c|c|}
\hline $\begin{array}{l}\text { Express são de } \\
\text { Incerteza }\end{array}$ & $\begin{array}{l}\text { Express ões Incerteza e } \\
\text { tomada decisão }\end{array}$ & $\mathbf{N}$ & Média & $\begin{array}{l}\text { Desv. } \\
\text { Pad. }\end{array}$ & $\mathbf{F}$ & $\begin{array}{l}\text { Sig. } \\
\text { (F) }\end{array}$ & C.S. & d.f. & $\begin{array}{l}\text { Sig. } \\
\text { (C.S.) }\end{array}$ \\
\hline \multirow{2}{*}{ Raz_Possível } & acredito & 56 & 43,179 & 15,809 & \multirow{2}{*}{0,541} & \multirow{2}{*}{0,464} & \multirow{2}{*}{0,143} & \multirow{2}{*}{1} & \multirow{2}{*}{0,706} \\
\hline & acredito fortemente & 39 & 42,179 & 18,453 & & & & & \\
\hline \multirow{2}{*}{ Raz_Prevista } & acredito & 56 & 50,000 & 18,856 & \multirow{2}{*}{0,042} & \multirow{2}{*}{0,838} & \multirow{2}{*}{0,725} & \multirow{2}{*}{1} & \multirow{2}{*}{0,394} \\
\hline & acredito fortemente & 39 & 47,205 & 18,315 & & & & & \\
\hline \multirow{2}{*}{ Espera } & acredito & 56 & 63,696 & 17,396 & \multirow{2}{*}{0,472} & \multirow{2}{*}{0,494} & \multirow{2}{*}{0,163} & \multirow{2}{*}{1} & \multirow{2}{*}{0,686} \\
\hline & acredito fortemente & 39 & 64,538 & 19,253 & & & & & \\
\hline \multirow{2}{*}{ Não_Espera } & acredito & 56 & 18,214 & 17,090 & \multirow{2}{*}{1,354} & \multirow{2}{*}{0,247} & \multirow{2}{*}{0,146} & \multirow{2}{*}{1} & \multirow{2}{*}{0,702} \\
\hline & acredito fortemente & 39 & 19,282 & 23,029 & & & & & \\
\hline \multirow{2}{*}{ Provável } & acredito & 56 & 61,500 & 21,801 & \multirow{2}{*}{2,284} & \multirow{2}{*}{0,134} & \multirow{2}{*}{4,444} & \multirow{2}{*}{1} & \multirow{2}{*}{0,035} \\
\hline & acredito fortemente & 39 & 69,795 & 18,828 & & & & & \\
\hline \multirow{2}{*}{ Altam_Prov } & acredito & 56 & 84,518 & 17,765 & \multirow{2}{*}{2,921} & \multirow{2}{*}{0,091} & \multirow{2}{*}{1,041} & \multirow{2}{*}{1} & \multirow{2}{*}{0,308} \\
\hline & acredito fortemente & 39 & 85,256 & 12,169 & & & & & \\
\hline \multirow{2}{*}{ Altam_Prov (*) } & acredito & 56 & 84,248 & 16,893 & & & & & \\
\hline & acredito fortemente & 39 & 86,538 & 11,014 & 7 & 8 & & 1 & 46 \\
\hline
\end{tabular}

Notas: $\mathrm{F}=$ estatística para a ANOVA; Sig. $(\mathrm{F})=$ Significância para a estatística $\mathrm{F}$, referente à ANOVA; C.S.= Chi-Square, estatística para o Teste Kruskal-Wallis; d.f.= graus de liberdade para a estatística de C.S., referente ao Teste Kruskal-Wallis; Sig. (C.S.)= Significância para a estatística C.S., referente ao Teste Kruskal-Wallis.

(*) Expressão analisada no segundo contexto 


\section{ENDEREÇO DOS AUTORES:}

\section{Fernanda Franco de Sá}

Universidade Federal de Uberlândia

Rua Curitiba, 186, Bairro Brasil

38.400-646 - Uberlândia - MG

\section{Rodrigo Fernandes Malaquias}

Universidade Federal de Uberlândia

Av. João Naves de Ávila, 2121, Bloco F, Sala 1F215, Santa Mônica

38.400-902 - Uberlândia - MG 